OPEN ACCESS

Edited by:

Peter J. Fried,

Beth Israel Deaconess Medical Center and Harvard Medical School,

United States

Reviewed by:

Stephanie Buss,

Beth Israel Deaconess Medical Center and Harvard Medical School,

United States

Caterina Motta,

Santa Lucia Foundation (IRCCS), Italy

Mar Cortes,

Icahn School of Medicine at Mount

Sinai, United States

*Correspondence:

Lorenzo Rocchi

l.rocchi@ucl.ac.uk

Specialty section:

This article was submitted to

Dementia and Neurodegenerative

Diseases,

a section of the journal

Frontiers in Neurology

Received: 17 July 2020

Accepted: 05 October 2020

Published: 03 November 2020

Citation:

Rawji V, Latorre A, Sharma N,

Rothwell JC and Rocchi L (2020) On the Use of TMS to Investigate the

Pathophysiology of

Neurodegenerative Diseases.

Front. Neurol. 11:584664.

doi: 10.3389/fneur.2020.584664

\section{On the Use of TMS to Investigate the Pathophysiology of Neurodegenerative Diseases}

\author{
Vishal Rawji, Anna Latorre, Nikhil Sharma, John C. Rothwell and Lorenzo Rocchi* \\ Department of Clinical and Movement Neurosciences, UCL Queen Square Institute of Neurology, University College London, \\ London, United Kingdom
}

Neurodegenerative diseases are a collection of disorders that result in the progressive degeneration and death of neurons. They are clinically heterogenous and can present as deficits in movement, cognition, executive function, memory, visuospatial awareness and language. Transcranial magnetic stimulation (TMS) is a non-invasive brain stimulation tool that allows for the assessment of cortical function in vivo. We review how TMS has been used for the investigation of three neurodegenerative diseases that differ in their neuroanatomical axes: (1) Motor cortex-corticospinal tract (motor neuron diseases), (2) Non-motor cortical areas (dementias), and (3) Subcortical structures (parkinsonisms). We also make four recommendations that we hope will benefit the use of TMS in neurodegenerative diseases. Firstly, TMS has traditionally been limited by the lack of an objective output and so has been confined to stimulation of the motor cortex; this limitation can be overcome by the use of concurrent neuroimaging methods such as EEG. Given that neurodegenerative diseases progress over time, TMS measures should aim to track longitudinal changes, especially when the aim of the study is to look at disease progression and symptomatology. The lack of gold-standard diagnostic confirmation undermines the validity of findings in clinical populations. Consequently, diagnostic certainty should be maximized through a variety of methods including multiple, independent clinical assessments, imaging and fluids biomarkers, and post-mortem pathological confirmation where possible. There is great interest in understanding the mechanisms by which symptoms arise in neurodegenerative disorders. However, TMS assessments in patients are usually carried out during resting conditions, when the brain network engaged during these symptoms is not expressed. Rather, a context-appropriate form of TMS would be more suitable in probing the physiology driving clinical symptoms. In all, we hope that the recommendations made here will help to further understand the pathophysiology of neurodegenerative diseases.

Keywords: transcrancial magnetic stimulation (TMS), neurodegenarative diseases, motor neuron disease (MND), amyotrophic lateral sclerosis, dementia, Alzheimer's disease, dementia with lewy bodies (DLB), Parkinson's disease 


\section{INTRODUCTION}

Neurodegenerative diseases constitute a heterogeneous group of disorders of the central nervous system characterized by gradual loss of structure and function of neurons, which eventually results in their death. This progressive damage leads to the development of a plethora of different signs and symptoms, based on the neural structures involved. Examples of neurodegenerative disorders include Parkinson's disease, Alzheimer's disease, and motor neuron disease. Whilst cell-based literature has informed about molecular mechanisms of disease (1), and bioinformatic approaches have informed of population-level exposure-disease risk associations (2), they do not explain physiological changes caused by neurodegenerative diseases in humans.

Transcranial magnetic stimulation (TMS) is a non-invasive brain stimulation technique, which uses a time-varying magnetic field to induce electrical currents in cortical areas of interest; these currents ultimately cause neuronal depolarization and action potential generation. Using TMS in humans allows the assessment of cortical function in vivo and can inform about the network characteristics of pathological scenarios, such as neurodegenerative diseases. This article reviews current literature to exemplify how TMS has been used to inform about neurodegenerative diseases. We focus on diseases affecting three different neuroanatomical axes to highlight the strengths and weaknesses of TMS:

1. Motor cortex-corticospinal tract (motor neuron diseases)

2. Non-motor cortical areas (dementias)

3. Subcortical structures (parkinsonisms)

By evaluating the strengths and weaknesses of TMS through this review, we offer a series of recommendations to the non-invasive brain stimulation community that will hopefully contribute to further development of the use of TMS in neurodegenerative diseases.

\section{TRANSCRANIAL MAGNETIC STIMULATION}

TMS is a non-invasive brain stimulation tool, which can specifically activate targeted brain regions. It is painless, welltolerated and allows investigators to probe the cerebral cortex in humans. The utility of TMS has traditionally been dependent on the ability to record the output, and much of the understanding of the effects of TMS on cortical circuits comes from stimulation of the primary motor cortex (M1). If applied over M1 at a suprathreshold stimulus intensity, TMS results in muscular contractions in contralateral muscles, in a somatotopically organized manner, which can be measured as electromyographic (EMG) activity using surface electrodes. The resultant output is called the motor evoked potential (MEP) and the ease with which MEPs can be produced using TMS is termed corticospinal excitability (CSE), as the major output stimulated using TMS is via the corticospinal tract (CST). The amplitude of the MEP varies as a function of the CSE at the time of stimulation. For example, CSE is increased if a subject expects that that the corresponding muscle will be activated and decreases if it is likely that the muscle will not be called into action (3).

Contrary to popular notions, CSE is not solely a measure of cortical excitability; the MEP is derived from cortical, spinal, nerve root, peripheral nerve, neuromuscular junction and muscle inputs (4-7). The cortical contribution to the MEP comes in the form of descending corticospinal volleys (8) generated after stimulation of cortical interneurons that synapse onto layer $\mathrm{V}$ CST neurons. These descending volleys summate upon spinal motor neurons and generate the MEP.

\section{TMS as a Tool to Investigate Motor Cortex Physiology}

The aim of this section is to give a brief account of the mechanisms underlying the TMS applications mentioned throughout the manuscript. Broadly, they can be categorized into four groups: single-pulse TMS (spTMS), paired-pulse TMS (ppTMS), connectivity measures, and repetitive TMS (rTMS).

As mentioned in the previous section, spTMS applied to M1 can be used to probe CSE through several measures derived from MEP. One such measure is the "threshold," i.e., the stimulus intensity required to evoke an MEP of a predetermined amplitude (usually between 50 and $200 \mu \mathrm{V}$ ); this can be probed at rest (resting motor threshold-RMT) and during muscle contraction (active motor threshold-AMT) (9). The peak-to-peak amplitude of MEPs also gives an indication of CSE and scales as a function of various cognitive processes such as effort (10), motor preparation $(3,11,12)$, and surprise (13). As a more accurate measure of CSE, it is possible to test the input-output $(\mathrm{I} / \mathrm{O})$ relationship between increasing TMS intensity and resulting MEP amplitude, thus estimating the gain of M1 (14). spTMS can also be used to assess M1 inhibitory mechanisms, putatively relying on $\mathrm{GABA}_{\mathrm{B}}$-mediated neurotransmission, by measuring the cortical silent period (CSP) [i.e., the interruption of voluntary muscle contraction caused by a single TMS pulse $(15,16)]$. Besides CSE, spTMS can also give information about integrity of the CST by assessing the central motor conduction time (CMCT) [i.e., the time taken for descending volleys to travel from M1 to anterior horn cells in the spinal cord (17)].

One shortcoming of spTMS is that MEPs obtained by single pulses give information only about the global excitability of CST neurons and associated intracortical circuitry. One way to overcome this limitation is by means of ppTMS, with stimuli applied through the same coil. By varying the interstimulus interval (ISI) between pulses, as well as the intensity of the first, conditioning stimulus, it is possible to probe different inhibitory or excitatory intracortical circuits. Examples of ppTMS paradigms are short intracortical inhibition (SICI), intracortical facilitation (ICF), and long intracortical inhibition (LICI), which are thought to probe $\mathrm{GABA}_{\mathrm{A}}$-mediated inhibition (14, $18)$, glutamatergic facilitation $(18,19)$, and GABAB-mediated inhibition $(20,21)$, respectively. A particular form of interaction, called short intracortical facilitation (SICF), can be obtained when the test pulse is followed, rather than preceded, by a conditioning pulses, with an ISI compatible with the latency 
difference between the first and the following descending wavelets induced by TMS $(22,23)$.

While TMS is often considered a focal source of stimulation, it is recognized that it may induce widespread activation via large-scale cortical networks. This principle can be used to assess functional connectivity by twin-coil TMS, where a conditioning pulse is delivered to a region of interest (ROI) and is followed by M1-TMS. With this approach, connectivity has been probed between M1 and a large number of ROIs, including ipsilateral $(24,25)$ and contralateral $(26,27)$ nodes of the motor network, as well as the contralateral cerebellar hemisphere $(28,29)$. M1 connectivity can also be probed with activation of sensory pathways by modality-specific stimuli. The most common approach is to pair electrical stimulation of a peripheral nerve with M1-TMS, which results in a form of MEP suppression named short-latency afferent inhibition (SAI) $(30,31)$. The same principle has been applied to investigate connectivity between M1 and visual $(32,33)$ or nociceptive (34) afferents.

TMS also has the ability to induce plastic changes to specific cortical sites and connected areas via rTMS protocols, which employ regular or patterned trains of TMS pulses to induce changes in cortical excitability that outlast the period of stimulation. These aftereffects are dependent on the intensity and frequency of stimulation; for example, rTMS applied at $<1 \mathrm{~Hz}$ induces MEP suppression, whereas stimulation at $>1 \mathrm{~Hz}$ induces MEP enhancement (35). Theta burst stimulation (TBS) is a variant of rTMS that induces plasticity by delivering bursts of stimulation (36-38). If bursts are separated by pauses, the protocol is termed intermittent TBS (iTBS) and is generally though to increase cortical excitability $(39,40)$; by contrast, in continuous TBS (cTBS), bursts are delivered without pauses, and the result is usually a decrease in cortical excitability (41-43). Paired associative stimulation (PAS) is another plasticity protocol that repeatedly pairs peripheral nerve stimulation with TMS over the contralateral M1 $(44,45)$, and is thought to operate through spike-timing dependent plasticity mechanisms (46) mediated by NMDA receptors $(47,48)$.

\section{MOTOR NEURON DISEASE}

Motor neuron disease (MND) is a fatal, neurodegenerative disease, which has no effective cure or treatment. It is characterized by progressive degeneration of upper (UMN) and lower motor neurons (LMN) that make up the CST and results in profound weakness of affected muscles. Different clinical subtypes of MND are derived from the differential involvement of UMNs and LMNs, such that amyotrophic lateral sclerosis (ALS) describes UMN and LMN degeneration, primary lateral sclerosis (PLS) refers to a pure UMN syndrome and primary muscular atrophy (PMA) and spinal-bulbar muscular atrophy (SBMA/SMA) are characterized by pure LMN damage. Bulbar and pseudobulbar palsy affect LMN and UMNs of the bulbar muscles, respectively.

The diagnosis of MND is one of exclusion and is made using a combination of history, clinical examination, and neurophysiological testing. The latter mostly involves needle EMG, which is able to assess degeneration of LMNs. However, EMG findings may not be entirely specific, due to the existence of disorders which can mimic MND in terms of damage to LMNs. Conversely, an electrophysiological marker of UMN function should differentiate MND from mimic disorders, as UMNs are affected in MND but not in mimics. TMS has been proposed to serve as a tool to assess UMN function in MND, as detailed in the following sections.

\section{Corticospinal Excitability Measured in Motor Neuron Disease}

As ALS is the most common form of MND, this is the most commonly examined model. From the perspective of spTMS measures, the RMT is lower in patients with MND than agematched healthy controls. However, some studies have found no difference in motor threshold between patients and healthy, agematched controls (49-52). Given the differential involvement of UMNs and LMNs in ALS, and that degeneration continues as disease progresses, the discrepancies in RMT may arise from differences in disease duration and UMN/LMN susceptibility. Indeed, the RMT is higher in patients with PLS than those with ALS and healthy controls (53) and raised in patients with mixed UMN and LMN signs (51). Conversely, the RMT is unchanged in patients with SMA, a LMN variant of MND (54). This bias considered, TMS studies seem to suggest corticospinal hyperexcitability in MND. However, patients with MND are excluded from TMS testing if MEPs cannot be generated, which is attributed to an unexcitable cortex. Calanie et al. have suggested that removal of this group of patients constitutes a form of selection bias, whereby individual patients with raised RMTs are excluded, thereby decreasing the group-level RMT (55).

The nature of this cortical hyperexcitability has been further investigated with ppTMS. A reliable finding from $\mathrm{ppTMS}$ studies has been an impairment of SICI in ALS (56-58), pointing to a breakdown of inhibitory transmission involving $\mathrm{GABA}_{\mathrm{A}}$ receptors. Other forms of cortical inhibition seem to be lacking as well in ALS, as suggested by shortening of CSP, which is commonly associated with $\mathrm{GABA}_{\mathrm{B}}$ receptors activity $(49,59,60)$, and by reduction of SAI (61). ppTMS measures of intracortical facilitation in ALS are less clear, with some studies showing increases (58, 62-64) and others showing no change $(50,56,65)$, compared to healthy controls.

\section{TMS Informs Clinical Features and Therapies in Motor Neuron Disease}

The split-hand phenomenon, typically found in ALS, describes the selective wasting of the thenar eminence of the hand over the hypothenar eminence (66). This could be explained by differential sensitivity of LMNs or UMNs to neurodegeneration. Indeed, the cortical representation of the abductor pollicis brevis (APB), a muscle of the thenar eminence, shows more excitability (measured as MEP/CMAP ratio) and less SICI compared to that of abductor digiti minimi, a muscle of the hypothenar eminence $(67,68)$. Whilst both the APB and flexor pollicis longus (FPL) muscles are supplied by the $\mathrm{C} 8$ and $\mathrm{T} 1$ roots via the median 
nerve, wasting preferentially affects the APB. This is corroborated by greater cortical innervation of the APB muscle than FPL $(69,70)$. Hence controlling for the peripheral component of the MEP by expressing the MEP as a proportion of the CMAP, and measuring MEPs from muscles supplied by the same roots and nerves suggests a cortical origin of the split-hand phenomenon.

Fasciculations are another key feature of MNDs and are thought to reflect muscle denervation resulting from LMN degeneration (71); as such, they are found is a large number of diseases involving the spinal cord. MND represents a special circumstance, since fasciculations occur in the presence of concurrent UMN and LMN degeneration. The origin of fasciculations in MND has been investigated by assessing central and peripheral nerve excitabilities using TMS. A significant, negative correlation between corticospinal inhibition (measured via the $\mathrm{GABA}_{\mathrm{B}}$-mediated CSP) and the frequency of fasciculations has been found in ALS but not in disorders characterized by peripheral nerve hyperexcitability (cramp-fasciculation syndrome, benign fasciculation syndrome, Morvan's syndrome and Isaac's syndrome), suggesting that fasciculations in ALS have a cortical contribution (72). The finding that cortical dysfunction contributes to fasciculations speaks to the top-down hypothesis of MND, where degeneration starts in the UMN and progresses along the motor neuroaxis.

Much attention in TMS-MND literature has been paid to the investigation of hand muscles, probably due to their large cortical representation. However, MND also affects other muscles, which are clinically relevant; degeneration of bulbar muscles can result in difficulties in swallowing, which confers a poorer prognosis (73). The involvement of bulbar muscles in MND has been assessed using TMS (74-77). In some studies, subclinical involvement of bulbar muscles measured by TMS has been observed, although the lack of longitudinal assessments makes the clinical relevance of these findings uncertain. One barrier to this approach is that some patients cannot tolerate intra-oral recording electrodes (78). Alternative strategies using less invasive approaches such as ultrasound may circumvent the difficulties posed by intra-oral electrodes (79).

Riluzole is the only disease-modifying drug that exists for MND (80). How Riluzole exerts its beneficial effect is currently unknown, although TMS studies have given some insights. TMS studies have confirmed that Riluzole exerts an antiglutamatergic effect by showing that its administration blocks NMDA-dependent plasticity induced by PAS (81). In addition, the administration of Riluzole restores impaired SICI in ALS $(65,82,83)$ and restores peripheral nerve excitability (assessed using peripheral nerve stimulation) (84).

\section{Distinguishing Different Types of Motor Neuron Disease}

TMS findings in other forms of MND are in keeping with the site of primary pathology; MEP amplitudes and CSP are both decreased in PLS than healthy controls, suggesting impaired corticospinal inhibition $(77,85)$. The RMT has been found to be higher in PLS than ALS $(53,86)$. In the study by Agarwal et al., patients with PLS had slower rates of disease progression than those with ALS; it may be the case that the lower RMT in ALS is a pathological manifestation of hyperexcitability, not as prominent in PLS, and hence suggests differential involvement of corticomotor neurons in PLS. On the other hand, the lower RMT in ALS may be due to LMN degeneration in ALS. The inability to differentiate these competing hypotheses highlights the limitation of the MEP as a readout of M1 function.

TMS studies in LMN diseases such as SMA and monomelic amyotrophy (MMA) are generally in keeping with the notion of UMN preservation (54,87-90). Specifically, the study by Farrar et al. has shown that measures of peripheral nerve excitability (CMAP amplitude, F-wave latency and frequency of F-waves occurrence), SICI and the MEP:M-wave ratio in patients with SMA is comparable to that found in healthy controls. Furthermore, SICI is greater in patients with SMA than those with ALS (88). These findings of retained corticomotoneuronal function are consistent in patients with MMA (90) and show that corticomotoneuronal dysfunction does not drive the LMN dysfunction in SMA and MMA. These studies indicate how TMS can provide insights into different motor neuron diseases by showing differential involvement of M1.

Given that genetic causes of MND exist, carriers of mutations in involved genes provide an interesting model to study presymptomatic MND, since the temporal consequences of neurodegeneration in MND can be explored as the disease manifests and develops. Corticospinal hyperexcitability, measured as reduced SICI and greater ICF, precedes the development of symptoms in presymptomatic SOD-1 (91) and C9orf72 $(92,93)$ carriers, suggesting that hyperexcitability represents a hallmark of degeneration. However, in other studies, SOD-1 mutation carriers have shown no difference in CSE measures compared to healthy controls (94). In a study by Turner et al., corticospinal hyperexcitability was found in patients with sporadic ALS but not SOD-1 ALS (95), suggesting that, despite similar clinical presentations in sporadic and familial ALS, the mechanisms by which neuronal degeneration occurs may differ.

\section{Distinguishing Motor Neuron Disease From Mimic Disorders}

The findings offered by TMS have culminated in the ability to use neurophysiological indices to differentiate MND from mimic disorders, under the assumption that UMNs are affected in the former but not the latter. SICI, ICF, and CSP have all been shown to differentiate ALS from mimics (such as multifocal motor neuropathy, chronic inflammatory demyelinating polyneuropathy, and distal hereditary motor neuronopathy) with receiving operator characteristics (ROC) area under the curve (AUC) of 0.76 for SICI (96). In a prospective, multicentre study by Menon et al., TMS was able to differentiate MND from mimic disorders with a sensitivity of $73.21 \%$ and a specificity of $80.88 \%$ (97). Consistent with previous literature, SICI was found to be the major neurophysiological parameter differentiating MND from mimics. The authors estimated that the diagnosis of MND could be improved by up to 15.8 months, a timeframe considered to be clinically significant, given the potentially short life expectancy. One flaw of this study is that 
TMS is unlikely to be used in isolation in the diagnosis of MND. The same group of investigators have developed a diagnostic index for ALS (ALSDI), which incorporates age, anatomical site of disease, CSP duration, CMAP amplitude and SICI to differentiate ALS from mimic disorders (98). The ALSDI was able to differentiate ALS from mimic disorders with $83.3 \%$ sensitivity, $84 \%$ specificity, and $83.5 \%$ diagnostic accuracy, which constitutes a mild increase relative to TMS alone (97). Of note, of 133 patients originally classed Awaji negative, 38 were reclassified as having ALS using the ALSDI criteria, of whom 31 went on to develop ALS.

These studies show that TMS may have a diagnostic role in MND, but there are some limitations to its clinical use. Many of the studies outlined thus far have excluded patients if MEPs could not be generated. For example, in the study by Menon et al., patients were excluded if the maximum MEP generated was $<1 \mathrm{mV}$ in amplitude (97). Under this criterion, and given the muscle wasting found in MND, a significant proportion of patients may not be eligible for assessment. As MND is a degenerative disease, it may be the case that the utility of TMS to inform diagnosis changes as the disease progresses (99). Hence it is likely that TMS may have a specific role to play at a certain point in the diagnostic pathway, for example clarifying UMN dysfunction when clinical examination is ambiguous.

\section{Lessons From Motor Cortical Stimulation in Motor Neuron Disease}

We have shown how assessing the function of the CST and M1 intracortical circuitry by means of TMS can give insight into MND pathophysiology. Corticospinal hyperexcitability, driven by a loss of intracortical inhibition, predominates as a key feature of MND pathophysiology. Extensive characterization of corticospinal changes in MND has resulted in a better understanding of clinical features, such as the split-hand phenomenon, and has promoted TMS as a diagnostic and prognostic tool for MND. Viewing TMS through the lens of MND has also highlighted some of its key limitations. Most notable is that the MEP is not a pure measure of UMN function and relies on the LMN system for its generation. Consequently, patients are routinely excluded from investigation if MEPs of a satisfactory amplitude cannot be generated. This means that TMS use is largely confined to early and mid-stage MND, when muscle wasting is limited.

\section{DEMENTIAS}

Dementia is an umbrella term for progressive disorders characterized by the loss of cognitive abilities such as memory, problem-solving, visuospatial awareness, behavior and language. Alzheimer's disease (AD), the most common cause of dementia, includes $\sim 60-80 \%$ of all dementias and is characterized mainly by memory impairment and loss of visuospatial awareness. Notable features of dementia with Lewy bodies (DLB), the third most common type of dementia after $\mathrm{AD}$ and vascular dementia, include impairment of executive function, fluctuating cognition, visual hallucinations, and parkinsonism. Another common form of dementia is Frontotemporal dementia (FTD), that describes degeneration of the frontal and temporal lobes and presents with impairment in decision-making and behavioral control, personality changes, and language decline. Interestingly, FTD has a genetic and pathological overlap with $\operatorname{MND}(100,101)$. In this review, we use these three conditions as an example to show how TMS can inform about diseases that do not primarily affect M1.

\section{Corticospinal Excitability in Dementias}

Traditionally, TMS has been limited to cortical areas where an output can be easily measured; these include M1 and the visual cortex. Consequently, much of the early TMS literature focussed on M1 stimulation to infer cortical dynamics of diseases that do not primarily affect the motor system, as in dementias.

Most studies report an increase in CSE in AD, but decreased (102) or normal (103, 104) CSE have also been found. Investigations with ppTMS have shown reduced intracortical inhibition but normal intracortical facilitation (103, 105107). The clinical relevance of corticospinal hyperexcitability is currently unknown. It may be possible that it represents a subclinical feature of M1 dysfunction. For instance, AD patients exhibit subtle locomotor and parkinsonian signs on examination (108), and cortical myoclonus, that is related to M1 hyperexcitability, is a common late feature of AD (109).

Cholinergic dysfunction is a hallmark of $\mathrm{AD}$ and implicated in its typical cognitive impairment (110). SAI pairs a peripheral sensory stimulus with a TMS pulse applied to the contralateral M1, which results in a decrement of the MEP compared to unconditioned TMS. Pharmacological manipulation has shown that SAI is sensitive to cholinergic neurotransmission (111) and as expected, SAI is reduced in $\operatorname{AD}(104,106,112-114)$. Moreover, anti-cholinesterase medications, commonly used in the management of $\mathrm{AD}$, restore impaired SAI $(112,115,116)$, although not all studies have confirmed this result $(31,117)$. Baseline SAI and increase in SAI after one dose of rivastigmine correlated with response to long-term treatment. Conversely, no SAI response to rivastigmine was associated with poor long-term clinical response to rivastigmine, thereby raising the possibility that SAI might predict the efficacy of future anti-cholinesterase treatment (116). Interestingly, anti-cholinesterase therapy also reverses impaired intracortical inhibition in $\mathrm{AD}(103,105)$, suggesting that cholinesterase inhibitors exert effects on noncholinergic circuits.

Only one study has investigated interneuronal circuits in DLB, showing that SICI and SAI are not statistically different from healthy controls (106). Early studies of CSE in patients with FTD showed no changes compared to healthy subjects $(103,118)$. However, a series of studies by Benussi et al. have investigated intracortical circuits in a large number of FTD patients, finding that both intracortical facilitation (ICF and SICF) and inhibition (SICI and LICI) are lower in FTD than in healthy controls (119-121).

\section{Plasticity Protocols in Dementias-Going Beyond Corticospinal Excitability}

rTMS protocols have allowed the study of synaptic dysfunction and impaired mechanisms of cortical plasticity in dementias, 
which are distinct from the changes in CSE. The aftereffects induced by rTMS applied over M1 are of smaller magnitude in patients with $\mathrm{AD}$ compared to healthy, age-matched control subjects, regardless of the protocols used and the direction of the effect; this finding is borne out over a variety of TMS plasticity protocols such as 1 and $5 \mathrm{~Hz}$ rTMS $(122,123)$, iTBS (124), and PAS $(114,125)$.

Smaller effects of several plasticity-inducing rTMS protocols suggest a global impairment in cortical plasticity that spans various different mechanisms. However, a study using variants of TBS has highlighted that specific types of plasticity may be preferentially affected in AD. Koch and coworkers found that the response to iTBS was significantly impaired in patients with $\mathrm{AD}$ relative to age-matched healthy controls. Conversely, the response to cTBS was not statistically different between groups. To explain their findings, the authors cited ex vivo work, where beta-amyloid oligomers obtained from cerebrospinal fluid (CSF) from patients with $\mathrm{AD}$ were shown to impair long-term potentiation (LTP) in rat CA3-CA1 synapses (126). In contrast, administration of beta-amyloid oligomers to the CA1 region in mice enhanced long-term depression (LTD) (127). The authors therefore posed that the impaired LTP-like plastic effects seen in humans was consistent with the effects of beta-amyloid pathology found in $\mathrm{AD}$ (124).

Whilst using evidence from animal and ex vivo research is useful in contextualizing TMS findings in patients, their inferences are weakened given that these mechanisms may not be applicable in vivo. Indeed, the terms LTP-like and LTD-like (rather than LTP and LTD) are used to describe changes in CSE observed in humans after plasticity protocols; this nomenclature is used due to the uncertainty that what is observed in humans is equivalent to what is observed in vitro. Therefore, concurrent measures of pathological features of disease, using fluid biomarkers, should be combined with TMS protocols to help bridge the gap between neuropathology and network neuroscience. By measuring CSF total Tau ( $t-T a u)$, phosphorylated Tau (p-Tau), and amyloid beta 42 (A $\beta 42)$ in AD patients undergoing $1 \mathrm{~Hz}$ M1 rTMS, Koch et al. have found that rTMS-induced inhibition correlated with t-Tau but not A $\beta 42$ (123). By measuring the extent of amyloid and Tau pathology in vivo, the authors have identified a potential pathological substrate responsible for impaired plasticity in $\mathrm{AD}$.

\section{TMS Measures Correlate With Cognitive Symptoms and Predicts Functional Decline}

It has been shown that some TMS measures of motor function correlate with clinical features in dementias. For instance, CSE, as measured by the RMT, correlates with cognitive severity in $\mathrm{AD}$ assessed by the mini mental state examination (MMSE) $(105,128-130)$. Furthermore, impairment in SAI is related to parkinsonian motor signs and CSF $A \beta_{42}$ levels (108). The increase in CSE with disease progression may be a consequence of accumulated pathology; indeed, neurofibrillary tangles, and amyloid plaques are also found in M1 (131).

The relevance of particular neurophysiological markers may differ among different types of dementia. For example, whilst SAI is reduced in both $\mathrm{AD}$ and DLB, it is correlated with behavioral disinhibition in AD and hallucinations in DLB (113), probably due to the diverse actions of acetylcholine. On the other hand, different symptoms within the same disorder may be related to different interneuronal circuits; Benussi et al. have found, in a large sample of patients with FTD, that negative symptoms (apathy and indifference) are correlated with ICF, whereas positive symptoms (irritability, impulsivity, and aggressiveness) are correlated with SICI (121).

Longitudinal assessments in patients with neurodegenerative diseases allow investigators to examine which markers may be predictive of clinical and functional decline. In a comprehensive study by Koch et al., CSF Tau, LTP-like plasticity (measured using iTBS) and APOE status (APOE polymorphic alleles are the main genetic determinants of $\mathrm{AD}$ ) were assessed in patients with AD. They found that the effect of iTBS was reversed in APOE3 patients, resulting in a decrease in post-protocol CSE, while APOE4 patients, that are at increased risk of AD compared with those carrying the more common E3 allele, did not show any significant changes in CSE after iTBS. In addition, higher CSF tau levels (an AD biomarker) were associated with a greater impairment of LTP-like plasticity and faster disease progression in patients with AD (132). The response to iTBS has also shown to predict disease progression in $\mathrm{AD}$ such that the greater the increase in CSE after iTBS, the lower the probability of disease progression (133).

SICI, SICF, and LICI, are all reduced in FTD. SAI is not different in patients with FTD compared to healthy subjects; this is to be expected given that SAI reflects cholinergic transmission, which is not typically involved in FTD. As well as being correlated with the FTLD-CDR (a clinical rating scale to measure FTD severity), it was found that less SICI is associated with greater clinical progression of FTD (120). The interpretation was that, rather than reflecting impairments of a specific interneuron circuit, these abnormalities reflect an inability to integrate two, closely timed pulses. As seen above in MND, patients with a genetic susceptibility to disease provide an insight into prodromal stages. To that end, SICI, ICF, and LICI have been shown to be altered before clinical onset in carriers of GRN and C9orf72 mutations. By calculating the estimated time from symptom onset, it was found that TMS measures can be altered up to three decades before the disease become manifest (119).

\section{Measuring Activity Outside of the Motor Cortex}

A limitation of the aforementioned studies is that they give information about motor intracortical dynamics, despite the primary site of pathology lying outside M1. Previous findings may therefore not be indicative of cortical function outside M1, and hence erroneous conclusions may be drawn about cortical function in dementias. To address this, investigators have combined TMS with other imaging modalities, which reflect cortical excitability outside of M1. For example, concurrent TMSEEG allows measurement from virtually all areas in the brain convexity. TMS pulses result in EEG perturbations, which can be measured in the time domain, as TMS-evoked potentials 
(TEPs), or in the time-frequency domain, as TMS-induced oscillations $(134,135)$. This novel approach has circumnavigated many of the traditional barriers to applying TMS outside of M1, and also allows to greatly expand the number of measured variables relative to TMS alone. TMS-EEG has been applied to patients with $\mathrm{AD}$ and mild cognitive impairment (MCI), finding a reduced P30 component in temporo-parietal regions, consistent with the site of primary pathology (136). Although in a small sample, the amplitude of the P30 component was able to differentiate patients with $\mathrm{AD}$ and MCI with an AUC $>0.90$. In addition, a smaller P30 component was associated with a greater clinical dementia rating score (137). spTMS to the left superior frontal cortex (Brodmann areas 6 and 8 ) found that excitability (TEP amplitude and significant current density) was reduced in patients with $\mathrm{AD}$ relative to healthy, age-matched controls. As this study measured TEPs in young and old healthy controls, Casarotto et al. surmised that TEPs were not abnormal unless affected by some pathological process, such as amyloid/tau deposition in $\mathrm{AD}$ (138). Although previous studies have found cortical excitability to be decreased in $\mathrm{AD}$ relative to healthy controls, cortical excitability (measured as the global mean field power-GMFP) was found to be higher in AD by Ferreri et al. (139). Further, better powered studies are required to clarify how cortical excitability, as measured by TMS-EEG, is affected in AD. In particular, one caveat of TEPs, including the $\mathrm{P} 30$ component, is that their amplitude can be spuriously decreased by the increased scalp-to-cortex distance in patients with cerebral atrophy. This factor should be accounted for in future studies using TMS-EEG in dementia.

TMS has seldomly been used to investigate functional connectivity in AD. By a twin-coil approach, altered parietomotor connectivity has been found in $\mathrm{AD}$, and this impairment is positively correlated with derangement in episodic memory and executive function (117). However, as mentioned twin coil approaches are limited to assessing connectivity between a ROI and M1, so they might not be necessarily informative of degeneration outside M1.

\section{Differentiating Types of Dementia}

As with MND, attempts have been made to stratify and diagnose dementias based on neurophysiological parameters. Neurophysiological assessment in patients with MCI with and without features of $\mathrm{AD}$ has found that $\mathrm{SAI}$ is lower in latter group. When incorporating other measures of intracortical function such as SICI and SICF, these neurophysiological parameters were able to differentiate the two with a sensitivity of $94.4 \%$ and specificity of $87.9 \%$ (140). The same approach has been used to differentiate three types of dementia: AD, DLB, and FTD. In this large study, a combination of TMS measures, including SICI, ICF, SAI, and LICI were incorporated into a random forest classifier, which was able to cluster dementias with high precision (0.86$0.92)$ and recall (0.93-0.98). Binary classification accuracy ranged from 0.89 to 0.92 , showing that TMS measures can help diagnose specific dementias with high accuracy (141).

Although these results are encouraging, it is unlikely that TMS alone will be used to diagnose specific dementias. It is therefore important to assess how TMS can change diagnostic certainty when approaching dementias. This has been assessed in the diagnosis of AD and FTD, whereby diagnostic certainty from three approaches was compared: clinical workup alone (demographic, clinical and neuropsychological evaluation), clinical workup + amyloid markers (CSF or amyloid positron emission tomographic imaging), and clinical workup + TMS intracortical connectivity measures. TMS measures were found to increase the discrimination between AD and FTD compared to clinical evaluation alone. The classification accuracy using clinical workup + TMS measures (AUC $=0.98)$ was similar to that of clinical workup + amyloid markers (AUC $=0.99)(142)$. This same approach has been used to differentiate MCI-AD, MCI-FTD, MCI-DLB, and MCI-other. The findings in this study replicate those in the previous study, that TMS measures increase the diagnostic certainty of MCI variants and that the increase is comparable to CSF fluid biomarkers (143). The non-invasive nature of TMS may be an advantage over fluid biomarkers, given that the addition of TMS measures or CSF biomarkers are comparable in diagnostic accuracy.

Some limitations of these studies should be mentioned. Firstly, they are retrospective, and neurophysiological parameters are fitted to explain known diagnoses. This commonly leads to overfitting of the data, which results in poor predictive performance in a prospective cohort. Secondly, according to clinico-pathological studies, specificity of clinical diagnosis of neurodegenerative disease, and especially tauopathies (including non-primary tauopathies such as AD), is low (144). Therefore, the reliability of TMS as diagnostic tool based on clinical diagnosis should be considered with caution in this context. An appropriate test for diagnostic utility of TMS in dementias would therefore be to perform a prospective study in a clinical setting, with comparisons of diagnostic accuracy with and without TMS.

\section{Lessons From TMS in Dementias}

TMS studies have established corticospinal dysfunction in an array of dementias that track the severity, symptomatology, and progression of disease. The addition of TMS measures to clinical assessment may enable an increase in diagnostic accuracy for dementia variants and shows potential for appropriate clinical translation, although appropriate prospective trials are required. One key caveat of TMS studies in dementia is that they usually study M1 function; the findings in M1 may not generalize to other cortical areas where pathology may be more clinically relevant. However, this view might be challenged by recent findings of widespread synaptic loss in AD, including pericentral regions, assessed with SV2A PET (145). Combination with other imaging modalities, such as EEG, has enabled the wider effects of TMS to be evaluated, allowing for cortical function of clinically significant areas to be assessed. Whilst yielding valuable insights into cortical excitability and functional connectivity outside of $\mathrm{M} 1$, only a small number of TMS-EEG studies have been performed in dementia. Future experiments should aim to further establish the wider effects of TMS and investigate the role of non-motor regions in dementias. 


\section{PARKINSONISMS}

The term parkinsonism describes a collection of disorders characterized by the presence of bradykinesia in combination with either rest tremor, rigidity or both. The most common form of parkinsonism is Parkinson's disease (PD), an idiopathic neurodegenerative disease neuropathologically distinguished by Lewy bodies and Lewy neurites, which are neuronal inclusions immunopositive for the protein $\alpha$-synuclein (146). Other neurodegenerative parkinsonian syndromes include multiple system atrophy (MSA), corticobasal syndrome (CBS), DLB and progressive supranuclear palsy (PSP). The common feature in these conditions is that they present with the cardinal parkinsonian features plus atypical signs, however they differ in the primary protein implicated in neurodegeneration or in the distribution of cortical proteins. For example, although PD, MSA, and DLB are $\alpha$-synucleinopathies, their pathology is significantly different, including the cell type involved (neurons in PD and DLB and oligodendroglia in MSA) and the degree of neuronal loss (only in selected regions in PD but widespread throughout many regions in MSA) (147). On the other side, both PSP and CBS have neuronal and glial lesions that are composed primarily of hyper phosphorylated tau $(148,149)$. However, the common denominator of all degenerative parkinsonisms is loss of dopaminergic neurons of the substantia nigra pars compacta. This section will discuss how TMS can inform about parkinsonian syndromes that primarily affect subcortical structures without a prominent involvement of higher-order brain areas.

\section{Corticospinal Excitability in Parkinsonisms}

The majority of TMS literature in parkinsonisms has been performed in PD, which generally present with increased CSE compared to healthy controls (150-152). Dissecting this increase in CSE with ppTMS has resulted in conflicting results, with some groups reporting normal intracortical inhibition and facilitation (153-156), whereas others describe abnormalities in these measures $(155,157-160)$. Sensorimotor interaction, as assessed with SAI, has also shown mixed results (161166). The conflicting outcomes may be partially explained by clinical features of $\mathrm{PD}$, which could be variable among patients. Inhibitory deficits have been found in early, untreated PD (167) and CSE hyperexcitability is greater in the more clinically affected hemisphere $(159,168)$. Failing to account for disease duration or clinical severity may explain the discrepancies in intracortical inhibition and facilitation; indeed, TMS measures vary as a function of symptomatology (see below).

As aforementioned, there are other neurodegenerative causes of parkinsonism that have been investigated using TMS. In a comparison with patients with PD, those with CBS and PSP have reduced SICI and raised SICF $(118,169,170)$. This is consistent with the cortical Tau pathology found in CBS and may therefore provide an objective marker of cortical involvement. Conte et al. have found a specific aberration of SICI but not ICF in patients with PSP, suggesting a specific impairment of inhibitory interneurons (171). Another example of differential cortical involvement comes from the comparison between Richardson syndrome and PSP-Parkinsonism; transcallosal inhibition is affected more in Richardson syndrome than PSP-Parkinsonism and PD (172), which may be due to higher cortical tau burden in Richardson's syndrome than PSP-Parkinsonims and PD. Furthermore, SAI has been found to differ between patients with PSP and those with PD, suggesting differential cholinergic involvement and sensorimotor interaction between these two $(162,170)$. Initial studies in MSA showed no sensory or motor threshold abnormalities, but did find prolonged CMCT in the lower limbs $(173,174)$, potentially owing to CST involvement seen in MSA. Sensorimotor processing and cholinergic function, as indexed by SAI, has been found to be significantly impaired in MSA compared to PD and correlates with clinical neuropsychiatric measures $(175,176)$.

Parkinsonisms due to an identifiable genetic cause differ from PD, both pathologically and clinically (177); this difference extends to electrophysiological assessments with TMS. CMCT is raised in patients with Parkin mutations (154, 178), implying subtle corticospinal dysfunction not found in PD. Patients with LRRK2 gene mutations exhibit less SICI and more ICF than patients with PD $(179,180)$. I/O curves and the CSP of patients with SNCA mutations differ from tremor-dominant PD but not akinetic PD (181). As with MND and dementias, genetic models of disease provide key insights into prodromal and preclinical disease pathophysiology. Indeed, subclinical Parkin and PINK1 mutation carriers display hyperexcitable premotorM1 connectivity measured with twin-coil TMS (182).

Patients with PD also show impairment in various different types of plasticity. LTP-like plasticity, as measured by MEP enhancement after iTBS, is impaired in PD (183-187), irrespective of medication status (188) or levodopa-induced dyskinesias (LIDs) (189). Spike-time-dependent plasticity, measured using PAS, is also impaired compared to healthy controls (190). However, some studies show a preservation of plasticity in patients with PD $(191,192)$. As with measures of CSE, the varied findings concerning plasticity in PD may have arisen due to uncontrolled variables. For example, there is an association between dopaminergic medication and cortical plasticity (193-195), and the presence or absence of LIDs (196).

Parkinsonisms have been investigated with stimulation of brain areas other than M1. Cerebellar stimulation is usually delivered in the form of rTMS, which has downstream effect on CSE (197), or spTMS, which can coupled with M1 TMS to obtain cerebellar-brain inhibition (CBI) (198). CBI is a form of ppTMS in which a conditioning stimulus over the cerebellum is followed by a TMS stimulus at M1, with an ISI of $\sim 5 \mathrm{~ms}$. CBI is achieved as a decrement in the MEP amplitude. Both cerebellar plasticity (199) and CBI (200) have been found to be impaired in patients with $\mathrm{PD}$, which has been interpreted as an impairment in cerebello-thalamo-cortical connectivity. In the study by $\mathrm{Ni}$ et al., postural tremor associated with $\mathrm{PD}$ was reset by cerebellar and M1 TMS, whereas rest tremor was reset by M1 TMS only, implying that the two types of tremor operate via different pathways (200). Schirinzi et al. found that CBI was impaired in patients if they had evidence of a dopaminergic deficit on imaging (187) suggesting that impairments in CBI may be a surrogate marker of dopamine deficiency. 


\section{TMS Correlates of Symptomatology in Parkinsonisms}

An effort has been made to investigate the clinical relevance of TMS measures in parkinsonisms to elucidate whether TMS abnormalities represent an epiphenomenon, rather than being related to any particular clinical feature or pathological process (201).

Bradykinesia is the cardinal feature of parkinsonism; it generally describes slowness of movements, which is reflected, for example, in the decrement in amplitude and velocity of repeated movements, or in increase reaction times (202-207). A steeper $\mathrm{I} / \mathrm{O}$ curve is found in patients with $\mathrm{PD}$, suggesting a greater gain of M1 than healthy controls (160). Furthermore, the slope of this curve correlates with clinical measures of bradykinesia. The authors proposed that, whilst counterintuitive, this increase in M1 gain may represent a compensatory mechanism to decreased excitatory input from the basal ganglia. Alternatively, the increase in M1 CSE could represent a form of noise, which competes with the motor instruction from the basal ganglia, thereby making movements more difficult to execute. If the latter hypothesis were true, then CSE should increase as the disease progresses (presumably as bradykinesia increases), but this has not been tested yet. A role of posterior parietal cortex (PPC)-M1 connectivity in bradykinesia has been proposed using a twin-coil TMS approach. PPC-M1 TMS at ISI 4 ms results in an increase in MEP amplitude in healthy controls, that is not found in patients with PD, irrespective of dopaminergic medication intake (208). By integrating this paradigm with behavior, the authors observed that greater strength of PPC-M1 connectivity was associated with faster movement execution in healthy controls, and PD patients on and off medication. The assessment of M1 function during movement therefore permits a contextually appropriate inference of the role of M1 CSE in bradykinesia.

A feature of parkinsonism with chronic levodopa treatment is the development of LIDs. LIDs are involuntary movements thought to arise as a consequence of nigrostriatal depletion and erratic cerebral levodopa concentrations. The presence of LIDs has generally been associated with M1 hyperexcitability, characterized by increased ICF and SICF (209-211) and decreased SICI and LICI $(211,212)$. LID generation appears to be linked to a wider dysfunction in the cortical motor network, as suggested by a weaker inhibitory functional connectivity between the inferior frontal cortex (IFC) and M1 (210). An interesting line of research has been devoted to clarifying the relationship between TMS measures and levodopa administration in patients with LIDs. Acute levodopa administration leads to an abnormal increase in excitability in the supplementary motor area (SMA) in patients with LIDs; this occurs in the cortex contralateral to the most affected body side, in comparison with the less affected hemisphere (213) and with PD patients without LIDs (214). It is well-known that LIDs are associated with chronic levodopa exposure. However, the latter might be necessary but not sufficient to cause LIDs (215), and it is not entirely clear to what extent degeneration linked to PD itself might be implicated. An indication on the role of levodopa on LED development comes from the study of Zittel et al. (216), who found that first-time exposure to levodopa exerts different effects on PMd-M1 inhibitory connectivity than chronic dopaminergic stimulation in $\mathrm{PD}$, suggesting a change in the responsiveness of cortico-cortical circuits during the course of disease. At least part of this change in responsiveness might be due to deranged control of cortical plasticity, as suggested by Morgante et al. (217). These authors found that LTP-like plasticity induced by PAS is restored by levodopa administration in non-dyskinetic, but not in dyskinetic PD patients. This suggests that abnormal synaptic plasticity in the M1 may play a role in the development of LIDs, a notion which has been confirmed by a number of other groups $(188,196)$.

\section{TMS Informs Therapies Used to Treat Parkinsonisms}

Dopaminergic replacement therapy is the mainstay of treatment for parkinsonisms, albeit mostly beneficial in PD compared to the other forms. As well as ameliorating parkinsonian motor features, it also results in restoration of aberrant neurophysiological measures such as SICI, LICI, and the CSP $(152,160,194,218,219)$. However, the correction of these abnormalities does not necessarily imply that specific inhibitory or excitatory circuits mediate the effects of dopaminergic therapy; rather, they could be in keeping with the restoration of normal movement.

Deep brain stimulation (DBS) is a surgical treatment used for advanced stage $\mathrm{PD}$, which involves the implantation of electrodes in order to stimulate subcortical nuclei of the basal ganglia. Common targets include the subthalamic nucleus (STN) and globus pallidus pars interna (GPi). Although the precise mechanism by which DBS exerts its therapeutic effect is not entirely known, there is evidence from functional neuroimaging that DBS normalizes activity and connectivity in the basal ganglia motor circuit $(220,221)$. This is consistent with TMS findings that STN (222-228) and GPi (224) DBS normalize aberrant M1 intracortical facilitation and inhibition.

Historically, functional neurosurgery involved lesioning of subcortical nuclei, which resulted in clinical benefit of motor symptoms. An important distinction is the difference between DBS and subthalamotomy/pallidotomy; the latter achieves clinical benefit by lesioning the STN or GPi, respectively. Despite targeting the same region, it is unknown whether the two methods achieve clinical benefit in the same way. Whilst neurophysiological measures are restored during DBS, they are not after pallidotomy (150). Hence, despite similar clinical outcome, DBS and lesioning approaches seem to have differing mechanisms of action. This suggests that stimulation in DBS actively alters cortico-basal ganglia circuits, a feature not found during OFF DBS conditions and lesioning. Additionally, cognitive side effects are common in DBS (229) whereas they are not in subthalamotomies (230). As shown by TMS studies, DBS has active effects on cortical functioning; this same phenomenon may be mediating the cognitive side effects during DBS.

Dopaminergic therapy and DBS exert similar clinical benefit for patients with PD, although there exist some notable differences in how these benefits arise. Similar improvements 
TABLE 1 | Summary of corticospinal changes stratified by neurodegenerative disease.

\begin{tabular}{|c|c|c|c|c|c|c|c|}
\hline & RMT & SICl & LICl & CSP (length) & SICF & ICF & SAI \\
\hline \multicolumn{8}{|l|}{ MND } \\
\hline ALS & Reduced & Reduced & - & Reduced & Raised/normal & Raised/normal & Reduced \\
\hline PLS & Raised & Normal & - & Reduced & - & - & - \\
\hline SMA/SBMA & Normal & Normal & - & - & Normal & Normal & - \\
\hline \multicolumn{8}{|l|}{ Dementias } \\
\hline$A D$ & Reduced & Reduced & Reduced & Increased/normal & Normal & Normal & Reduced \\
\hline DLB & Normal & Normal & Normal & - & - & Reduced & Reduced/normal \\
\hline FTD & Normal & Reduced & Reduced & Normal & Reduced & Reduced & Normal \\
\hline \multicolumn{8}{|c|}{ Parkinsonisms } \\
\hline PD & Reduced/normal & Mixed & Mixed & Mixed & Mixed & Mixed & Mixed \\
\hline CBS & Normal & Reduced & - & - & Raised & Reduced & Normal \\
\hline PSP & Normal & Reduced & - & Reduced & Raised & Normal & Normal \\
\hline MSA & Normal & Reduced & - & Raised & - & Normal & Reduced \\
\hline
\end{tabular}

ALS, amyotrophic lateral sclerosis; PLS, primary lateral sclerosis; SMA/SBMA, spinal-bulbar muscular atrophy; AD, Alzheimer's disease; DLB, dementia with Lewy bodies; FTD, frontotemporal dementia; PD, Parkinson's disease; CBS, corticobasal syndrome; PSP, progressive supranuclear palsy; MSA, multiple system atrophy; "-", not tested.

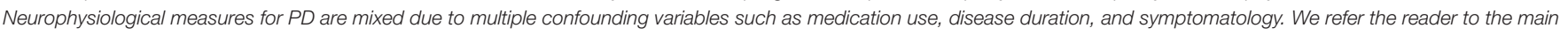
test for elaboration.

in SICI and CSP during STN DBS, apomorphine and levodopa are observed, suggesting that they share some common mechanisms in clinical improvement $(224,228)$. On the other hand, concurrent TMS-EEG shows that cortical excitability, as measured by the GMFP from 45 to $80 \mathrm{~ms}$ and high-alpha oscillatory activity are increased during STN DBS; conversely, GMFP from 80 to $130 \mathrm{~ms}$ and beta oscillatory activity are increased during DBS and levodopa (231). However, the clinical relevance of this finding is unclear, given that no correlation with clinical symptoms was performed in the study. It may be the case that the change in oscillatory activity and cortical excitability represents an epiphenomenon of levodopa administration or STN DBS, not related to clinical improvement.

The studies mentioned thus far have suggested that therapies to treat parkinsonisms act via cortical mechanisms. Whilst apomorphine restores SICI and CSP, it has no effect on Hoffman's reflex-a measure of spinal motor neuron excitability (218). On the other hand, STN DBS alters spinal excitability by restoring TMS-induced facilitation of Hoffman's reflex, showing that STN stimulation restores facilitatory drive to the spinal motoneuron pool (227).

\section{Lessons From TMS in Parkinsonisms}

TMS in parkinsonisms informs about the role of one node (M1) in the cortico-basal ganglia-cortical network. Hence, findings from these experiments infer the effect of basal ganglia pathology on overall motor output. Contrary to MNDs, isolated measures of cortical function are less useful in informing disease pathophysiology of parkinsonisms. Instead, TMS is better suited when a specific question or aspect of disease is being investigated. For example, TMS has enabled subtle differences in therapies for parkinsonisms to be appreciated and has given insights into particular symptoms, such as LIDs and bradykinesia. Going forward, TMS may be useful to inform how novel therapies for parkinsonism, such as focused ultrasound therapy, act to exert clinical benefit.

\section{RECOMMENDATIONS FOR THE USE OF TMS IN NEURODEGENERATIVE DISEASES}

This review has covered how TMS has been used to give insights into the pathophysiology of neurodegenerative diseases affecting cortical and subcortical structures (summarized in Table 1). Below, we synthesize some of the salient points gleaned in this review for researchers wishing to investigate neurodegenerative diseases in the future (Figure 1).

\section{Recommendation 1: TMS Should Form Part of a Multi-Modal Approach to Investigate Neurodegenerative Diseases}

Traditionally, there has been no robust outcome measure for TMS outside of M1. Consequently, TMS experiments in disease states infer cortical function from M1-evoked MEPs, even in diseases where M1 is not primarily involved, such as dementias and parkinsonisms. Doing so might limit inferences about those TMS results to M1 only and away from sites of primary pathology. Additionally, any inferences made regarding M1 excitability may be confounded by several factors. One example is represented by inputs from other cortical areas, which are probably active during both resting conditions and active behavior $(3,11,12)$. A second issue pertains to the influence of spinal cord circuitry on MEP (7), which is usually unmeasured and that can be a significant problem if cortical and spinal cord damage coexist. The limitations outlined above can be overcome by combining TMS with neuroimaging approaches to give a more comprehensive view of brain function. For example, the use of concurrent TMS and EEG has shown that temporo-parietal excitability is decreased in patients with $\mathrm{AD}$ compared to healthy 


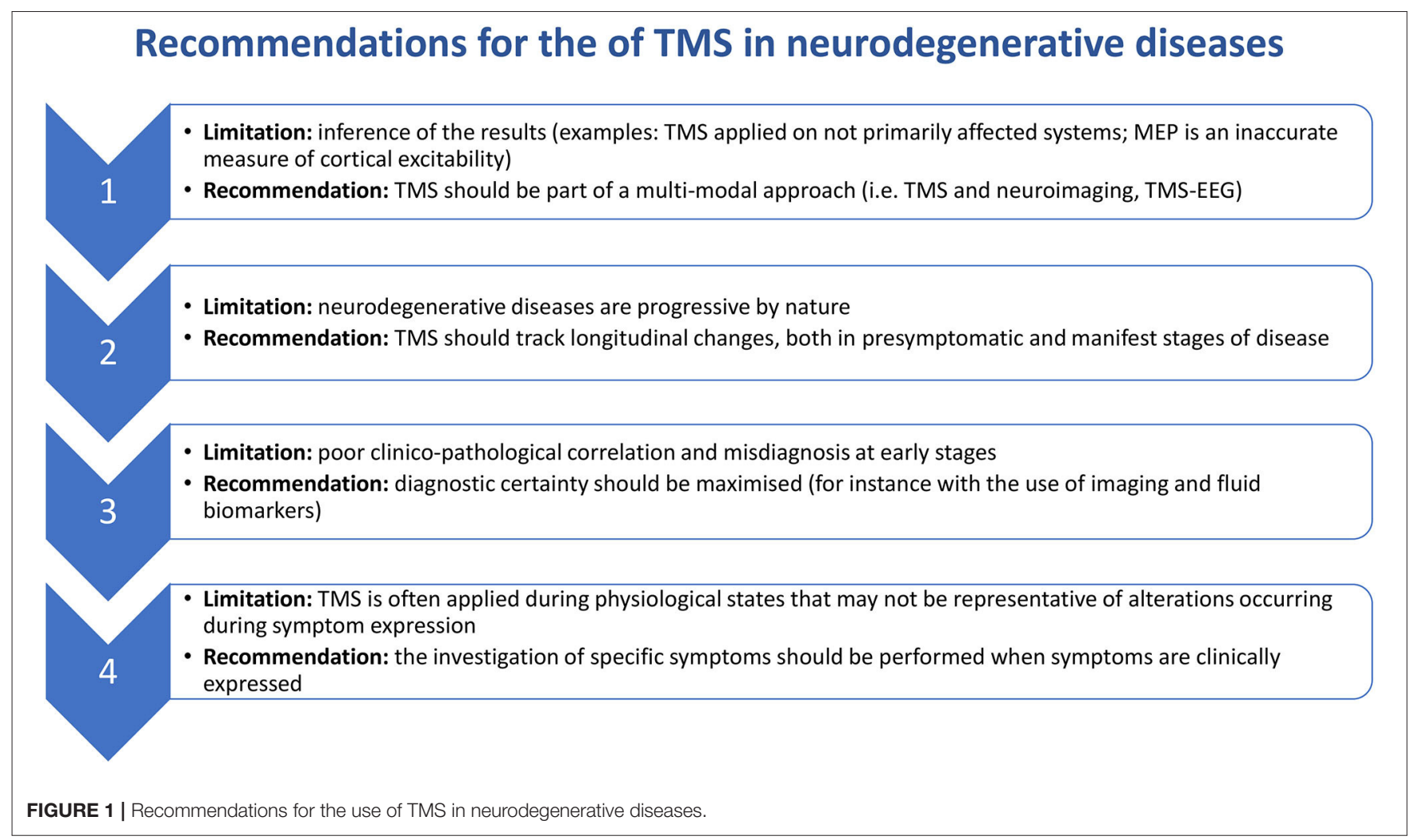

controls (136), a finding that would not have been possible with M1 TMS alone. Due to its ability to measure cortical function without the confounds of peripheral sources, TMS-EEG may also allow to circumnavigate the caveats posed by MEPs in conditions of impaired neuromuscular function, such as MND (232).

\section{Recommendation 2: TMS Should Track Longitudinal Changes in Neurodegenerative Diseases}

It is in the nature of neurodegenerative diseases to be progressive and evolve over time. As well as worsening of particular symptoms, new ones can develop, and diagnoses can even be revised. For example, patients can clinically resemble PD at onset, but progression might be compatible with other forms of parkinsonism. This raises a number of important points: firstly, the progression of symptoms and development of new ones allows longitudinal assessments to be of value in neurodegenerative diseases. Whilst longitudinal assessments in individuals would be ideal, the variability in TMS measures over time may be problematic $(233,234)$. An alternative might be to apply TMS to populations of patients to characterize disease progression, and then track how disease progression changes under different treatments. Longitudinal assessments will enable identification of which TMS measures scale with disease severity or symptomatology and which do not (235). It is also noteworthy that neurodegenerative disorders can have a long presymptomatic phase during which biomarkers can be positive; therefore, another possible application of TMS could be to track changes during this early stage.

\section{Recommendation 3: Diagnostic Certainty of Clinical Population Should Be Maximized}

The third point concerns the diagnosis of patients enrolled into TMS studies. Pathological confirmation is considered the gold-standard of diagnosis but is not always viable. In most studies, the diagnosis of a particular neurodegenerative disorder is made upon clinical assessment; in some, two or more neurologists make an assessment to increase diagnostic certainty. However, clinico-pathological correlation is poor (236) and, as explained earlier, neurodegenerative diseases change over time, and a diagnosis at one point in time may be revised later on. These inaccurate diagnoses add noise to the patients' sample and hence the same pathological process might not be assessed in all patients. Longitudinal assessments are desirable, as they increase diagnostic accuracy. Furthermore, if a diagnosis is revised over time, then measures at the first time point may represent preclinical/pre-diagnostic markers. In all, multimodal approaches to confirm diagnosis should be encouraged. Additionally, validation of outcome measures, such as imaging (237) and fluid biomarkers $(238,239)$ developed to confirm diagnosis of neurodegenerative diseases, should be further prompted. 


\section{Recommendation 4: TMS Investigating Symptomatology Should Be Applied During Symptom Expression}

Usually, correlations are investigated between clinical features and TMS measures recorded at rest. However, resting-state physiology may not be representative of alterations occurring during symptom expression. For example, CSE measures at rest in patients with parkinsonism may not be applicable to bradykinesia, which occurs during movement. A more appropriate assessment of how corticospinal physiology relates to bradykinesia would be assessing it during repetitive, continuous movements, when bradykinesia manifests. A corollary in $\mathrm{AD}$ would be to employ temporo-parietal TMS during behavioral tasks of memory recall; note that this would require an additional neuroimaging tool such as concurrent EEG to measure the output of TMS. In all, the investigation of symptoms in neurodegenerative diseases should aim toward one where the symptom is expressed and hence the network driving said symptom is assessed. Casula et al., for example, combined TMS-EEG with a speeded tapping task to assess how changes in cortical oscillatory activity are related to impairments in movement generation in Huntington's disease (HD). They found that stronger oscillatory activity corresponded to better performance (240), showing that the timing accuracy of cortical synchronization and desynchronisation may be a physiological basis for clinical features of HD.

\section{CONCLUSION}

TMS is a powerful tool to investigate corticospinal and cortical physiology in vivo. This review has summarized how TMS has given valuable insights into the pathophysiology of neurodegenerative diseases. We made several recommendations for how TMS should be employed in the future to better

\section{REFERENCES}

1. Slanzi A, Iannoto G, Rossi B, Zenaro E, Constantin G. in vitro models of neurodegenerative diseases. Front Cell Dev Biol. (2020) 8:328. doi: $10.3389 /$ fcell.2020.00328

2. Storm CS, Kia DA, Almramhi M, Wood NW. Using mendelian randomization to understand and develop treatments for neurodegenerative disease. Brain Commun. (2020) 2:fcaa031. doi: 10.1093/braincomms/fcaa031

3. Hannah R, Cavanagh SE, Tremblay S, Simeoni S, Rothwell JC. Selective suppression of local interneuron circuits in human motor cortex contributes to movement preparation. J Neurosci. (2018) 38:1264-1276. doi: 10.1523/JNEUROSCI.2869-17.2017

4. Terao Y, Ugawa Y, Uesaka Y, Hanajima R, Gemba-Shimizu K, Ohki $\mathrm{Y}$, et al. Input-output organization in the hand area of the human motor cortex. Electroencephalogr Clin Neurophys. (1995) 97:375-81. doi: 10.1016/0924-980X(95)00179-O

5. Rothwell JC. Techniques and mechanisms of action of transcranial stimulation of the human motor cortex. J Neurosci Methods. (1997) 74:11322. doi: 10.1016/S0165-0270(97)02242-5

6. Chen R, Cros D, Curra A, Di Lazzaro V, Lefaucheur JP, Magistris MR, et al. The clinical diagnostic utility of transcranial magnetic stimulation: report of an IFCN committee. Clin Neurophysiol. (2008) 119:50432. doi: 10.1016/j.clinph.2007.10.014 inform the pathophysiology of neurodegenerative diseases. The usefulness of TMS has traditionally been limited by the lack of an objective output and hence has been confined to stimulation of M1; this limitation can be overcome by the use of concurrent neuroimaging methods such as EEG. Seeing as neurodegenerative diseases evolve over time, TMS measures should aim to track longitudinal changes, especially when the aim of the study is to look at disease progression and symptomatology. Although TMS measures have been shown to aid in the diagnosis of neurodegenerative diseases, the lack of gold-standard diagnostic confirmation undermines the validity of the findings. Consequently, diagnostic certainty should be maximized through a variety of methods including multiple, independent clinical assessments, imaging and fluids biomarkers and post-mortem pathological confirmation where possible. There is great interest in understanding the mechanisms by which symptoms arise in neurodegenerative disorders. However, TMS assessments in patients are usually carried out during resting conditions, when the brain network engaged during these symptoms is not expressed. Rather, a context-appropriate form of TMS would be more suitable in probing the physiology driving clinical symptoms. In all, we hope that the recommendations made here will help to further understand the pathophysiology of neurodegenerative diseases.

\section{AUTHOR CONTRIBUTIONS}

VR, AL, and LR wrote the manuscript. NS and JR provided valuable insights in the direction of the manuscript. All authors contributed to the article and approved the submitted version.

\section{ACKNOWLEDGMENTS}

VR would like to thank Catherine Storm for her review and comments on this manuscript.

7. Bestmann S, Krakauer JW. The uses and interpretations of the motorevoked potential for understanding behavior. Exp Brain Res. (2015) 233:67989. doi: 10.1007/s00221-014-4183-7

8. Di Lazzaro V, Profice P, Ranieri F, Capone F, Dileone M, Oliviero A, et al. I-wave origin and modulation. Brain Stimul. (2012) 5:51225. doi: 10.1016/j.brs.2011.07.008

9. Rossini PM, Burke D, Chen R, Cohen LG, Daskalakis Z, Di Iorio $\mathrm{R}$, et al. Non-invasive electrical and magnetic stimulation of the brain, spinal cord, roots and peripheral nerves: Basic principles and procedures for routine clinical and research application. An updated report from an I.F.C.N. Committee. Clin Neurophysiol. (2015) 126:1071107. doi: 10.1016/j.clinph.2015.02.001

10. Cos I, Duque J, Cisek P. Rapid prediction of biomechanical costs during action decisions. J Neurophysiol. (2014) 112:125666. doi: 10.1152/jn.00147.2014

11. Ibáñez J, Hannah R, Rocchi L, Rothwell J. Premovement suppression of corticospinal excitability may be a necessary part of movement preparation. Cerebral Cortex. (2019) 30:2910-23. doi: 10.1093/cercor/bhz283

12. Rawji V, Modi S, Latorre A, Rocchi L, Hockey L, Bhatia K, et al. Impaired automatic but intact volitional inhibition in primary tic disorders. Brain. (2020) 143:906-19. doi: 10.1093/brain/awaa024

13. Bestmann S, Harrison LM, Blankenburg F, Mars RB, Haggard P, Friston $\mathrm{KJ}$, et al. influence of uncertainty and surprise on human corticospinal 
excitability during preparation for action. Curr Biol. (2008) 18:77580. doi: 10.1016/j.cub.2008.04.051

14. Ganos C, Rocchi L, Latorre A, Hockey L, Palmer C, Joyce EM, et al. Motor cortical excitability during voluntary inhibition of involuntary tic movements. Mov Disord. (2018) 33:1804-9. doi: 10.1002/mds.27479

15. Fuhr P, Agostino R, Hallett M. Spinal motor neuron excitability during the silent period after cortical stimulation. Electroencephalogr Clin Neurophysiol. (1991) 81:257-62. doi: 10.1016/0168-5597(91)90011-L

16. McDonnell MN, Orekhov Y, Ziemann U. The role of GABAB receptors in intracortical inhibition in the human motor cortex. Exp Brain Res. (2006) 173:86-93. doi: 10.1007/s00221-006-0365-2

17. Udupa K, Chen R. Central motor conduction time. Handb Clin Neurol. (2013) 116:375-86. doi: 10.1016/B978-0-444-53497-2.00031-0

18. Kujirai T, Caramia MD, Rothwell JC, Day BL, Thompson PD, Ferbert A, et al. Corticocortical inhibition in human motor cortex. J Physiol. (1993) 471:501-19. doi: 10.1113/jphysiol.1993.sp019912

19. Tokimura H, Ridding MC, Tokimura Y, Amassian VE, Rothwell JC. Short latency facilitation between pairs of threshold magnetic stimuli applied to human motor cortex. Electroencephalogr Clin Neurophysiol. (1996) 101:26372. doi: 10.1016/0924-980X(96)95664-7

20. Berardelli A, Rona S, Inghilleri M, Manfredi M. Cortical inhibition in parkinson's disease. A study with paired magnetic stimulation. Brain. (1996) 119:71-7. doi: 10.1093/brain/119.1.71

21. Erro R, Rocchi L, Antelmi E, Liguori R, Tinazzi M, Berardelli A, et al. High frequency somatosensory stimulation in dystonia: evidence fordefective inhibitory plasticity. Mov Disord. (2018) 33:1902-9. doi: 10.1002/mds.27470

22. Chen R, Garg R. Facilitatory i wave interaction in proximal arm and lower limb muscle representations of the human motor cortex. J Neurophysiol. (2000) 83:1426-34. doi: $10.1152 /$ jn.2000.83.3.1426

23. Hannah R, Rocchi L, Tremblay S, Wilson E, Rothwell JC. Pulse width biases the balance of excitation and inhibition recruited by transcranial magnetic stimulation. Brain Stimul. (2020) 13:536-8. doi: 10.1016/j.brs.2020.01.011

24. Davare M. Dissociating the role of ventral and dorsal premotor cortex in precision grasping. $J$ Neurosci. (2006) 26:22608. doi: 10.1523/JNEUROSCI.3386-05.2006

25. Davare M, Rothwell JC, Lemon RN. Causal connectivity between the human anterior intraparietal area and premotor cortex during grasp. Curr Biol. (2010) 20:176-81. doi: 10.1016/j.cub.2009.11.063

26. Ferbert A, Priori A, Rothwell JC, Day BL, Colebatch JG, Marsden CD. Interhemispheric inhibition of the human motor cortex. J Physiol. (1992) 453:525-46. doi: 10.1113/jphysiol.1992.sp019243

27. Koch G, Franca M, Fernandez Del Olmo M, Cheeran B, Milton R, Alvarez Sauco M, et al. Time course of functional connectivity between dorsal premotor and contralateral motor cortex during movement selection. $J$ Neurosci. (2006) 26:7452-9. doi: 10.1523/JNEUROSCI.1158-06.2006

28. Ugawa Y, Uesaka Y, Terao Y, Hanajima R, Kanazawa I. Magnetic stimulation over the cerebellum in humans: magnetic cerebellar stimulation. Ann Neurol. (1995) 37:703-13. doi: 10.1002/ana.410370603

29. Rocchi L, Latorre A, Ibanez Pereda J, Spampinato D, Brown KE, Rothwell J, et al. A case of congenital hypoplasia of the left cerebellar hemisphere and ipsilateral cortical myoclonus. Mov Disord. (2019) 34:17457. doi: $10.1002 / \mathrm{mds} .27881$

30. Tokimura H, Di Lazzaro V, Tokimura Y, Oliviero A, Profice P, Insola $\mathrm{A}$, et al. Short latency inhibition of human hand motor cortex by somatosensory input from the hand. J Physiol. (2000) 523:50313. doi: 10.1111/j.1469-7793.2000.t01-1-00503.x

31. Hwang YT, Rocchi L, Hammond P, Hardy CJD, Warren JD, Ridha $\mathrm{BH}$, et al. Effect of donepezil on transcranial magnetic stimulation parameters in Alzheimer's disease. Alzheimers Dement. (2018) 4:1037. doi: 10.1016/j.trci.2018.02.001

32. Suppa A, Rocchi L, Li Voti P, Papazachariadis O, Casciato S, Di Bonaventura C, et al. The photoparoxysmal response reflects abnormal early visuomotor integration in the human motor cortex. Brain Stimul. (2015) 8:115161. doi: $10.1016 /$ j.brs.2015.05.013

33. Suppa A, Li Voti P, Rocchi L, Papazachariadis O, Berardelli A. Early visuomotor integration processes induce LTP/LTD-Like plasticity in the human motor cortex. Cerebral Cortex. (2015) 25:703-12. doi: 10.1093/cercor/bht264
34. Suppa A, Biasiotta A, Belvisi D, Marsili L, La Cesa S, Truini A, et al. Heat-evoked experimental pain induces long-term potentiation-like plasticity in human primary motor cortex. Cerebral Cortex. (2013) 23:194251. doi: $10.1093 /$ cercor/bhs 182

35. Dayan E, Censor N, Buch ER, Sandrini M, Cohen LG. Noninvasive brain stimulation: from physiology to network dynamics and back. Nat Neurosci. (2013) 16:838-44. doi: 10.1038/nn.3422

36. Huang Y-Z, Edwards MJ, Rounis E, Bhatia KP, Rothwell JC. Theta burst stimulation of the human motor cortex. Neuron. (2005) 45:2016. doi: 10.1016/j.neuron.2004.12.033

37. Tremblay S, Hannah R, Rawji V, Rothwell JC. Modulation of iTBS aftereffects via concurrent directional TDCS: a proof of principle study. Brain Stimul. (2017) 10:744-7. doi: 10.1016/j.brs.2017.03.009

38. Rocchi L, Ibáñez J, Benussi A, Hannah R, Rawji V, Casula E, et al. Variability and predictors of response to continuous theta burst stimulation: a TMSEEG study. Front Neurosci. (2018) 12:400. doi: 10.3389/fnins.2018.00400

39. Conte A, Rocchi L, Nardella A, Dispenza S, Scontrini A, Khan N, et al. Thetaburst stimulation-induced plasticity over primary somatosensory cortex changes somatosensory temporal discrimination in healthy humans. PLoS ONE. (2012) 7:e32979. doi: 10.1371/journal.pone.0032979

40. Conte A, Rocchi L, Ferrazzano G, Leodori G, Bologna M, Li Voti $\mathrm{P}$, et al. Primary somatosensory cortical plasticity and tactile temporal discrimination in focal hand dystonia. Clin Neurophysiol. (2014) 125:53743. doi: 10.1016/j.clinph.2013.08.006

41. Nardella A, Rocchi L, Conte A, Bologna M, Suppa A, Berardelli A. Inferior parietal lobule encodes visual temporal resolution processes contributing to the critical flicker frequency threshold in humans. PLoS ONE. (2014) 9:e98948. doi: 10.1371/journal.pone.0098948

42. Georgiev D, Rocchi L, Tocco P, Speekenbrink M, Rothwell JC, Jahanshahi M. Continuous theta burst stimulation over the dorsolateral prefrontal cortex and the pre-sma alter drift rate and response thresholds respectively during perceptual decision-making. Brain Stimul. (2016) 9:601-8. doi: 10.1016/j.brs.2016.04.004

43. Méndez JC, Rocchi L, Jahanshahi M, Rothwell J, Merchant H. Probing the timing network: a continuous theta burst stimulation study of temporal categorization. Neuroscience. (2017) 356:167-75. doi: 10.1016/j.neuroscience.2017.05.023

44. Stefan K. Induction of plasticity in the human motor cortex by paired associative stimulation. Brain. (2000) 123:57284. doi: 10.1093/brain/123.3.572

45. Conte A, Li Voti P, Pontecorvo S, Quartuccio ME, Baione V, Rocchi L, et al. Attention-related changes in short-term cortical plasticity help to explain fatigue in multiple sclerosis. Mult Scler. (2016) 22:135966. doi: $10.1177 / 1352458515619780$

46. Markram H, Gerstner W, Sjöström PJ. Spike-Timing-dependent plasticity: a comprehensive overview. Front Syn Neurosci. (2012) 4:2. doi: $10.3389 /$ fnsyn. 2012.00002

47. Stefan K, Kunesch E, Benecke R, Cohen LG, Classen J. Mechanisms of enhancement of human motor cortex excitability induced by interventional paired associative stimulation. J Physiol. (2002) 543:699-708. doi: 10.1113/jphysiol.2002.023317

48. Wolters A, Sandbrink F, Schlottmann A, Kunesch E, Stefan K, Cohen LG, et al. A temporally asymmetric hebbian rule governing plasticity in the human motor cortex. J Neurophysiol. (2003) 89:2339-45. doi: 10.1152/jn.00900.2002

49. Siciliano G, Manca ML, Sagliocco L, Pastorini E, Pellegrinetti A, Sartucci F, et al. Cortical silent period in patients with amyotrophic lateral sclerosis. $J$ Neurol Sci. (1999) 169:93-7. doi: 10.1016/S0022-510X(99)00223-3

50. Zanette G, Tamburin S, Manganotti P, Refatti N, Forgione A, Rizzuto N. Changes in motor cortex inhibition over time in patients with amyotrophic lateral sclerosis. J Neurol. (2002) 249:1723-8. doi: 10.1007/s00415-002-0926-7

51. Mills KR. The natural history of central motor abnormalities in amyotrophic lateral sclerosis. Brain. (2003) 126:2558-66. doi: 10.1093/brain/awg260

52. Khedr EM, Ahmed MA, Hamdy A, Shawky OA. Cortical excitability of amyotrophic lateral sclerosis: transcranial magnetic stimulation study. Neurophysiol Clin. (2011) 41:73-9. doi: 10.1016/j.neucli.2011. 03.001 
53. Agarwal S, Highton-Williamson E, Caga J, Matamala JM, Dharmadasa T, Howells J, et al. Primary lateral sclerosis and the amyotrophic lateral sclerosis-frontotemporal dementia spectrum. J Neurol. (2018) 265:181928. doi: 10.1007/s00415-018-8917-5

54. Vucic S, Kiernan MC. Cortical excitability testing distinguishes Kennedy's disease from amyotrophic lateral sclerosis. Clin Neurophysiol. (2008) 119:1088-96. doi: 10.1016/j.clinph.2008.01.011

55. Calancie B, Young E, Watson ML, Wang D, Alexeeva N. Superconditioning TMS for examining upper motor neuron function in MND. Exp Brain Res. (2019) 237:2087-103. doi: 10.1007/s00221-019-05573-4

56. Zanette G, Tamburin S, Manganotti P, Refatti N, Forgione A, Rizzuto N. Different mechanisms contribute to motor cortex hyperexcitability in amyotrophic lateral sclerosis. Clin Neurophysiol. (2002) 113:168897. doi: 10.1016/S1388-2457(02)00288-2

57. Vucic S, Cheah BC, Kiernan MC. Defining the mechanisms that underlie cortical hyperexcitability in amyotrophic lateral sclerosis. Exp Neurol. (2009) 220:177-82. doi: 10.1016/j.expneurol.2009.08.017

58. Van den Bos MAJ, Higashihara M, Geevasinga N, Menon P, Kiernan MC, Vucic S. Imbalance of cortical facilitatory and inhibitory circuits underlies hyperexcitability in ALS. Neurology. (2018) 91:e1669-e76. doi: 10.1212/WNL.0000000000006438

59. Attarian S, Pouget J, Schmied A. Covariation of corticospinal efficiency and silent period in motoneuron diseases. Muscle Nerve. (2006) 34:17888. doi: 10.1002/mus. 20570

60. Menon P, Geevasinga N, van den Bos M, Yiannikas C, Kiernan MC, Vucic S. Cortical hyperexcitability and disease spread in amyotrophic lateral sclerosis. Eur J Neurol. (2017) 24:816-24. doi: 10.1111/ene.13295

61. Cengiz B, Fidanci H, Kiyak Keçeli Y, Baltaci H, KuruoGlu R. Impaired shortand long-latency afferent inhibition in amyotrophic lateral sclerosis. Muscle Nerve. (2019) 59:699-704. doi: 10.1002/mus.26464

62. Geevasinga N, Menon P, Yiannikas C, Kiernan MC, Vucic S. Diagnostic utility of cortical excitability studies in amyotrophic lateral sclerosis. Eur J Neurol. (2014) 21:1451-7. doi: 10.1111/ene.12422

63. Menon P, Kiernan MC, Vucic S. Cortical hyperexcitability precedes lower motor neuron dysfunction in ALS. Clin Neurophysiol. (2015) 126:8039. doi: 10.1016/j.clinph.2014.04.023

64. Grieve SM, Menon P, Korgaonkar MS, Gomes L, Foster S, Kiernan MC, et al. Potential structural and functional biomarkers of upper motor neuron dysfunction in ALS. Amyotr Lateral Sclerosis Front Degen. (2016) 17:8592. doi: 10.3109/21678421.2015.1074707

65. Stefan K, Kunesch E, Benecke R, Classen J. Effects of riluzole on cortical excitability in patients with amyotrophic lateral sclerosis. Ann Neurol. (2001) 49:536-9. doi: 10.1002/ana.107

66. Wilbourn AJ. The "split hand syndrome". Muscle Nerve. (2000) 23:138. doi: 10.1002/(SICI)1097-4598(200001)23:1<138::AID-MUS22>3.0.CO;2-7

67. Weber M, Eisen A, Stewart H, Hirota N. The split hand in ALS has a cortical basis. J Neurol Sci. (2000) 180:66-70. doi: 10.1016/S0022-510X(00) 00430-5

68. Menon P, Kiernan MC, Vucic S. Cortical dysfunction underlies the development of the split-hand in amyotrophic lateral sclerosis. PLOS ONE. (2014) 9:e87124. doi: 10.1371/journal.pone.0087124

69. Bae JS, Menon P, Mioshi E, Kiernan MC, Vucic S. Cortical hyperexcitability and the split-hand plus phenomenon: pathophysiological insights in ALS. Amyotr Lateral Sclerosis Front Degen. (2014) 15:250-6. doi: 10.3109/21678421.2013.872150

70. Ludolph AC, Emilian S, Dreyhaupt J, Rosenbohm A, Kraskov A, Lemon $\mathrm{RN}$, et al. Pattern of paresis in ALS is consistent with the physiology of the corticomotoneuronal projections to different muscle groups. J Neurol Neurosurg Psychiatry. (2020) 2020:323331. doi: 10.1136/jnnp-2020-323331

71. Mills KR. The basics of electromyography. J Neurol Neurosurg Psychiatry. (2005) 76:ii32-5. doi: 10.1136/jnnp.2005.069211

72. Noto Y, Simon NG, Selby A, Garg N, Shibuya K, Shahrizaila N, et al. Ectopic impulse generation in peripheral nerve hyperexcitability syndromes and amyotrophic lateral sclerosis. Clin Neurophysiol. (2018) 129:97480. doi: 10.1016/j.clinph.2018.01.061

73. Chiò A, Logroscino G, Hardiman O, Swingler R, Mitchell D, Beghi E, et al. Prognostic factors in ALS: A critical review. Amyotr Lateral Sclerosis. (2009) 10:310-23. doi: 10.3109/17482960802566824
74. Urban PP, Wicht S, Hopf HC. Sensitivity of transcranial magnetic stimulation of cortico-bulbar vs. cortico-spinal tract involvement in Amyotrophic Lateral Sclerosis (ALS). J Neurol. (2001) 248:850-5. doi: 10.1007/s004150170068

75. Desiato MT, Bernardi G, Hagi H A, Boffa L, Caramia MD. Transcranial magnetic stimulation of motor pathways directed to muscles supplied by cranial nerves in amyotrophic lateral sclerosis. Clin Neurophysiol. (2002) 113:132-40. doi: 10.1016/S1388-2457(01)00724-6

76. Cho J-Y, Sung JJ, Min J-H, Lee K-W. Clinical utility of trapezius muscle studies in the evaluation of amyotrophic lateral sclerosis. J Clin Neurosci. (2006) 13:908-12. doi: 10.1016/j.jocn.2006.01.044

77. Bocci T, Briscese L, Giorli E, Pecori C, Sartucci F. Tongue's motor evoked potentials in the diagnosis of Primary Lateral Sclerosis (PLS): preliminary report. J Neurol Sci. (2012) 316:67-71. doi: 10.1016/j.jns.2012.01.028

78. Urban P. Corticobulbar tract involvement in amyotrophic lateral sclerosis. A transcranial magnetic stimulation study. Brain. (1998) 121:1099108. doi: 10.1093/brain/121.6.1099

79. Kaczmarczyk I, Rawji V, Rothwell JC, Hodson-Tole E, Sharma N. Comparison between conventional electrodes and ultrasound monitoring to measure TMS evoked muscle contraction. bioRxiv. (2020). doi: 10.1101/2020.02.07.938837

80. Bensimon G, Lacomblez L, Meininger V. A controlled trial of riluzole in amyotrophic lateral sclerosis. $N$ Engl J Med. (1994) 330:585-91. doi: 10.1056/NEJM199403033300901

81. Ceccanti M, Onesti E, Rubino A, Cambieri C, Tartaglia G, Miscioscia A, et al. Modulation of human corticospinal excitability by paired associative stimulation in patients with amyotrophic lateral sclerosis and effects of Riluzole. Brain Stimul. (2018) 11:775-81. doi: 10.1016/j.brs.2018.02.007

82. Desiato MT, Palmieri MG, Giacomini P, Scalise A, Arciprete F, Caramia MD. The effect of riluzole in amyotrophic lateral sclerosis: a study with cortical stimulation. J Neurol Sci. (1999) 169:98-107. doi: 10.1016/S0022-510X(99)00225-7

83. Geevasinga N, Menon P, Ng K, Van Den Bos M, Byth K, Kiernan MC, et al. Riluzole exerts transient modulating effects on cortical and axonal hyperexcitability in ALS. Amyotr Lateral Sclerosis Front Degen. (2016) 17:580-8. doi: 10.1080/21678421.2016.1188961

84. Vucic S, Lin CS-Y, Cheah BC, Murray J, Menon P, Krishnan AV, et al. Riluzole exerts central and peripheral modulating effects in amyotrophic lateral sclerosis. Brain. (2013) 136:1361-70. doi: 10.1093/brain/awt085

85. Floyd AG, Yu QP, Piboolnurak P, Tang MX, Fang Y, Smith WA, et al. Transcranial magnetic stimulation in ALS: utility of central motor conduction tests. Neurology. (2009) 72:498504. doi: 10.1212/01.wnl.0000341933.97883.a4

86. Floeter MK, Mills R. Progression in primary lateral sclerosis: a prospective analysis. Amyotr Lateral Sclerosis. (2009) 10:33946. doi: 10.3109/17482960903171136

87. Enterzari-Taher M, Eisen A, Stewart H, Nakajima M. Abnormalities of cortical inhibitory neurons in amyotrophic lateral sclerosis. (1997) 20:6571. doi: 10.1002/(SICI)1097-4598(199701)20:1<65::AID-MUS9>3.0.CO;2-F

88. Farrar M, Vucic S, Johnston H, Kiernan MC. corticomotoneuronal integrity and adaptation in spinal muscular atrophy. Arch Neurol. (2012) 69:467. doi: 10.1001/archneurol.2011.1697

89. Boelmans K, Kaufmann J, Schmelzer S, Vielhaber S, Kornhuber M, Münchau A, et al. Hirayama disease is a pure spinal motor neuron disorder-a combined DTI and transcranial magnetic stimulation study. J Neurol. (2013) 260:540-8. doi: 10.1007/s00415-012-6674-4

90. Matamala JM, Geevasinga N, Huynh W, Dharmadasa T, Howells J, Simon NG, et al. Cortical function and corticomotoneuronal adaptation in monomelic amyotrophy. Clin Neurophysiol. (2017) 128:1488-95. doi: 10.1016/j.clinph.2017.05.005

91. Vucic S, Nicholson GA, Kiernan MC. Cortical hyperexcitability may precede the onset of familial amyotrophic lateral sclerosis. Brain. (2008) 131:154050. doi: 10.1093/brain/awn071

92. Geevasinga N, Menon P, Nicholson GA, Ng K, Howells J, Kril $\mathrm{JJ}$, et al. Cortical function in asymptomatic carriers and patients with C9orf72 amyotrophic lateral sclerosis. JAMA Neurol. (2015) 72:1268. doi: 10.1001/jamaneurol.2015.1872

93. Schanz O, Bageac D, Braun L, Traynor BJ, Lehky TJ, Floeter MK. Cortical hyperexcitability in patients with C9ORF72 mutations: relationship to 
phenotype: hyperexcitability in C9orf72 ALS. Muscle Nerve. (2016) 54:2649. doi: 10.1002/mus.25047

94. Vucic S, Winhammar JMC, Rowe DB, Kiernan MC. Corticomotoneuronal function in asymptomatic SOD-1 mutation carriers. Clin Neurophysiol. (2010) 121:1781-5. doi: 10.1016/j.clinph.2010.02.164

95. Turner MR. Abnormal cortical excitability in sporadic but not homozygous D90A SOD1 ALS. J Neurol Neurosurg Psychiatry. (2005) 76:127985. doi: $10.1136 /$ jnnp. 2004.054429

96. Vucic S, Cheah BC, Yiannikas C, Kiernan MC. Cortical excitability distinguishes ALS from mimic disorders. Clin Neurophysiol. (2011) 122:1860-6. doi: 10.1016/j.clinph.2010.12.062

97. Menon P, Geevasinga N, Yiannikas C, Howells J, Kiernan MC, Vucic S. Sensitivity and specificity of threshold tracking transcranial magnetic stimulation for diagnosis of amyotrophic lateral sclerosis: a prospective study. Lancet Neurol. (2015) 14:478-84. doi: 10.1016/S1474-4422(15)00014-9

98. Geevasinga N, Howells J, Menon P, van den Bos M, Shibuya K, Matamala JM, et al. Amyotrophic lateral sclerosis diagnostic index: toward a personalized diagnosis of ALS. Neurology. (2019) 92:e53647. doi: 10.1212/WNL.0000000000006876

99. Attarian S, Vedel J-P, Pouget J, Schmied A. Progression of cortical and spinal dysfunctions over time in amyotrophic lateral sclerosis. Muscle Nerve. (2008) 37:364-75. doi: 10.1002/mus.20942

100. Clark CM, Forman MS. Frontotemporal lobar degeneration with motor neuron disease: a clinical and pathological spectrum. Arch Neurol. (2006) 63:489. doi: 10.1001/archneur.63.4.489

101. Neumann M, Sampathu DM, Kwong LK, Truax AC, Micsenyi MC, Chou TT, et al. Ubiquitinated TDP-43 in frontotemporal lobar degeneration and amyotrophic lateral sclerosis. Science. (2006) 314:130-3. doi: 10.1126/science. 1134108

102. Perretti A, Grossi D, Fragassi N, Lanzillo B, Nolano M, Pisacreta $\mathrm{AI}$, et al. Evaluation of the motor cortex by magnetic stimulation in patients with Alzheimer disease. J Neurol Sci. (1996) 135:317. doi: 10.1016/0022-510X(95)00244-V

103. Pierantozzi M, Panella M, Palmieri MG, Koch G, Giordano A, Marciani MG, et al. Different TMS patterns of intracortical inhibition in early onset Alzheimer dementia and frontotemporal dementia. Clin Neurophysiol. (2004) 115:2410-8. doi: 10.1016/j.clinph.2004.04.022

104. Nardone R, Bergmann J, Kronbichler M, Kunz A, Klein S, Caleri F, et al. Abnormal short latency afferent inhibition in early Alzheimer's disease: a transcranial magnetic demonstration. J Neural Transm. (2008) 115:155762. doi: $10.1007 /$ s00702-008-0129-1

105. Liepert J, Bär KJ, Meske U, Weiller C. Motor cortex disinhibition in Alzheimer's disease. Clin Neurophysiol. (2001) 112:143641. doi: 10.1016/S1388-2457(01)00554-5

106. Nardone R, Bratti A, Tezzon F. Motor cortex inhibitory circuits in dementia with Lewy bodies and in Alzheimer's disease. J Neural Transm. (2006) 113:1679-84. doi: 10.1007/s00702-006-0551-1

107. Hoeppner J, Wegrzyn M, Thome J, Bauer A, Oltmann I, Buchmann J, et al. Intra- and inter-cortical motor excitability in Alzheimer's disease. J Neural Transm. (2012) 119:605-12. doi: 10.1007/s00702-011-0738-y

108. Schirinzi T, Di Lorenzo F, Sancesario GM, Di Lazzaro G, Ponzo V, Pisani A, et al. Amyloid-mediated cholinergic dysfunction in motor impairment related to Alzheimer's disease. JAD. (2018) 64:525-32. doi: 10.3233/JAD-171166

109. Chen J-Y, Stern Y, Sano M, Mayeux R. Cumulative risks of developing extrapyramidal signs, psychosis, or myoclonus in the course of Alzheimer's disease. Arch Neurol. (1991) 48:1141-3. doi: 10.1001/archneur.1991.00530230049020

110. Hampel H, Mesulam M-M, Cuello AC, Farlow MR, Giacobini E, Grossberg GT, et al. The cholinergic system in the pathophysiology and treatment of Alzheimer's disease. Brain. (2018) 141:1917-33. doi: 10.1093/brain/awy132

111. Nardone R, Golaszewski S, Ladurner G, Tezzon F, Trinka E. A review of transcranial magnetic stimulation in the in vivo functional evaluation of central cholinergic circuits in dementia. Dement Geriatr Cogn Disord. (2011) 32:18-25. doi: $10.1159 / 000330016$

112. Di Lazzaro V, Oliviero A, Tonali PA, Marra C, Daniele A, Profice P, et al. Noninvasive in vivo assessment of cholinergic cortical circuits in
AD using transcranial magnetic stimulation. Neurology. (2002) 59:3927. doi: 10.1212/WNL.59.3.392

113. Marra C, Quaranta D, Profice P, Pilato F, Capone F, Iodice F, et al. Central cholinergic dysfunction measured "in vivo" correlates with different behavioral disorders in Alzheimer's disease and dementia with Lewy body. Brain Stimulation. (2012) 5:533-8. doi: 10.1016/j.brs.2011.08.009

114. Terranova C, Sant'Angelo A, Morgante F, Rizzo V, Allegra R, Arena MG, et al. Impairment of sensory-motor plasticity in mild Alzheimer's disease. Brain Stimul. (2013) 6:62-6. doi: 10.1016/j.brs.2012.01.010

115. Di Lazzaro V. Motor cortex hyperexcitability to transcranial magnetic stimulation in Alzheimer's disease. J Neurol Neurosurg Psychiatry. (2004) 75:555-9. doi: 10.1136/jnnp.2003.018127

116. Di Lazzaro V. Neurophysiological predictors of long term response to $\mathrm{AChE}$ inhibitors in AD patients. J Neurol Neurosurg Psychiatry. (2005) 76:10649. doi: 10.1136/jnnp.2004.051334

117. Ferreri F, Pasqualetti P, Määttä S, Ponzo D, Guerra A, Bressi F, et al. Motor cortex excitability in Alzheimer's disease: a transcranial magnetic stimulation follow-up study. Neurosci Lett. (2011) 492:948. doi: 10.1016/j.neulet.2011.01.064

118. Alberici A, Bonato C, Calabria M, Agosti C, Zanetti O, Miniussi C, et al. The contribution of TMS to frontotemporal dementia variants. Acta Neurol Scand. (2008) 118:275-80. doi: 10.1111/j.1600-0404.2008.01017.x

119. Benussi A, Gazzina S, Premi E, Cosseddu M, Archetti S, Dell'Era $\mathrm{V}$, et al. Clinical and biomarker changes in presymptomatic genetic frontotemporal dementia. Neurobiol Aging. (2019) 76:133-40. doi: 10.1016/j.neurobiolaging.2018.12.018

120. Benussi A, Dell'Era V, Cantoni V, Cotelli MS, Cosseddu M, Spallazzi M, et al. TMS for staging and predicting functional decline in frontotemporal dementia. Brain Stimul. (2020) 13:386-92. doi: 10.1016/j.brs.2019.11.009

121. Benussi A, Dell'Era V, Cantoni V, Cotelli MS, Cosseddu M, Spallazzi M, et al. Neurophysiological correlates of positive and negative symptoms in frontotemporal dementia. JAD. (2020) 73:1133-42. doi: 10.3233/JAD-190986

122. Inghilleri $\mathrm{M}$, Conte $\mathrm{A}$, Frasca $\mathrm{V}$, Scaldaferri $\mathrm{N}$, Gilio $\mathrm{F}$, Santini $\mathrm{M}$, et al. Altered response to rTMS in patients with Alzheimer's disease. Clin Neurophysiol. (2006) 117:103-9. doi: 10.1016/j.clinph.2005. 09.016

123. Koch G, Esposito Z, Kusayanagi H, Monteleone F, Codecá C, Di Lorenzo F, et al. CSF tau levels influence cortical plasticity in alzheimer's disease patients. JAD. (2011) 26:181-6. doi: 10.3233/JAD-2011-110116

124. Koch G, Di Lorenzo F, Bonnì S, Ponzo V, Caltagirone C, Martorana A. Impaired LTP- but not LTD-like cortical plasticity in Alzheimer's disease patients. JAD. (2012) 31:593-9. doi: 10.3233/JAD-2012-120532

125. Di Lorenzo F, Ponzo V, Motta C, Bonnì S, Picazio S, Caltagirone C, et al. Impaired spike timing dependent cortico-cortical plasticity in Alzheimer's disease patients. JAD. (2018) 66:983-91. doi: 10.3233/JAD-180503

126. Klyubin I, Betts V, Welzel AT, Blennow K, Zetterberg H, Wallin A, et al. Amyloid $\beta$ protein dimer-containing human csf disrupts synaptic plasticity: prevention by systemic passive immunization. J Neurosci. (2008) 28:4231. doi: 10.1523/JNEUROSCI.5161-07.2008

127. Li S, Hong S, Shepardson NE, Walsh DM, Shankar GM, Selkoe D. Soluble oligomers of amyloid $\beta$ protein facilitate hippocampal long-term depression by disrupting neuronal glutamate uptake. Neuron. (2009) 62:788801. doi: 10.1016/j.neuron.2009.05.012

128. Alagona G, Bella R, Ferri R, Carnemolla A, Pappalardo A, Costanzo E, et al. Transcranial magnetic stimulation in Alzheimer disease: motor cortex excitability and cognitive severity. Neurosci Lett. (2001) 314:5760. doi: 10.1016/S0304-3940(01)02288-1

129. Pennisi G, Alagona G, Ferri R, Greco S, Santonocito D, Pappalardo A, et al. Motor cortex excitability in Alzheimer disease: one year follow-up study. Neurosci Lett. (2002) 329:293-6. doi: 10.1016/S0304-3940(02)00701-2

130. Khedr EM, Ahmed MA, Darwish ES, Ali AM. The relationship between motor cortex excitability and severity of Alzheimer's disease: a transcranial magnetic stimulation study. Neurophysiol Clin. (2011) 41:107-13. doi: 10.1016/j.neucli.2011.03.002

131. Selden NR, Gitelman DR, Salamon-Murayama N, Parrish TB, Mesulam MM. Trajectories of cholinergic pathways within the cerebral hemispheres of the human brain. Brain. (1998) 121(Pt 12):2249-57. doi: 10.1093/brain/121.12.2249 
132. Koch G, Di Lorenzo F, Loizzo S, Motta C, Travaglione S, Baiula M, et al. CSF tau is associated with impaired cortical plasticity, cognitive decline and astrocyte survival only in APOE4-positive Alzheimer's disease. Sci Rep. (2017) 7:13728. doi: 10.1038/s41598-017-14204-3

133. Motta C, Di Lorenzo F, Ponzo V, Pellicciari MC, Bonnì S, Picazio S, et al. Transcranial magnetic stimulation predicts cognitive decline in patients with Alzheimer's disease. J Neurol Neurosurg Psychiatry. (2018) 89:123742. doi: 10.1136/jnnp-2017-317879

134. Tremblay S, Rogasch NC, Premoli I, Blumberger DM, Casarotto S, Chen R, et al. Clinical utility and prospective of TMS-EEG. Clin Neurophysiol. (2019) 130:802-44. doi: 10.1016/j.clinph.2019.01.001

135. Casula EP, Maiella M, Pellicciari MC, Porrazzini F, D'Acunto A, Rocchi L, et al. Novel TMS-EEG indexes to investigate interhemispheric dynamics in humans. Clin Neurophysiol. (2020) 131:70-7. doi: 10.1016/j.clinph.2019.09.013

136. Julkunen P, Jauhiainen AM, Westerén-Punnonen S, Pirinen E, Soininen H, Könönen M, et al. Navigated TMS combined with EEG in mild cognitive impairment and Alzheimer's disease: a pilot study. J Neurosci Methods. (2008) 172:270-6. doi: 10.1016/j.jneumeth.2008.04.021

137. Julkunen P, Jauhiainen AM, Knnen M, Pääkknen A, Karhu J, Soininen H. Combining transcranial magnetic stimulation and electroencephalography may contribute to assess the severity of Alzheimer's disease. Int J Alzheimer's Dis. (2011) 2011:1-9. doi: 10.4061/2011/654794

138. Casarotto S, Määttä S, Herukka S-K, Pigorini A, Napolitani M, Gosseries $\mathrm{O}$, et al. Transcranial magnetic stimulation-evoked EEG/cortical potentials in physiological and pathological aging. NeuroReport. (2011) 22:5927. doi: 10.1097/WNR.0b013e328349433a

139. Ferreri F, Vecchio F, Vollero L, Guerra A, Petrichella S, Ponzo D, et al. Sensorimotor cortex excitability and connectivity in Alzheimer's disease: a TMS-EEG Co-registration study. Hum Brain Mapping. (2016) 37:208396. doi: 10.1002/hbm. 23158

140. Padovani A, Benussi A, Cantoni V, Dell'Era V, Cotelli MS, Caratozzolo $\mathrm{S}$, et al. Diagnosis of mild cognitive impairment due to Alzheimer's disease with transcranial magnetic stimulation. JAD. (2018) 65:22130. doi: 10.3233/JAD-180293

141. Benussi A, Grassi M, Palluzzi F, Koch G, Di Lazzaro V, Nardone R, et al. Classification accuracy of transcranial magnetic stimulation for the diagnosis of neurodegenerative dementias. Ann Neurol. (2020) 87:394404. doi: 10.1002/ana.25677

142. Benussi A, Alberici A, Ferrari C, Cantoni V, Dell'Era V, Turrone R, et al. The impact of transcranial magnetic stimulation on diagnostic confidence in patients with Alzheimer disease. Alz Res Ther. (2018) 10:94. doi: 10.1186/s13195-018-0423-6

143. Padovani A, Benussi A, Cotelli MS, Ferrari C, Cantoni V, Dell'Era V, et al. Transcranial magnetic stimulation and amyloid markers in mild cognitive impairment: impact on diagnostic confidence and diagnostic accuracy. Alz Res Ther. (2019) 11:95. doi: 10.1186/s13195-019-0555-3

144. Elahi FM, Miller BL. A clinicopathological approach to the diagnosis of dementia. Nat Rev Neurol. (2017) 13:457-76. doi: 10.1038/nrneurol.2017.96

145. Mecca AP, Chen M-K, O’Dell RS, Naganawa M, Toyonaga T, Godek TA, et al. In vivo measurement of widespread synaptic loss in Alzheimer's disease with SV2A PET. Alzheimers Dement. (2020) 16:974-82. doi: 10.1002/alz.12097

146. Dickson DW. Parkinson's disease and Parkinsonism: neuropathology. Cold Spring Harbor Persp Med. (2012) 2:a009258. doi: 10.1101/cshperspect.a009258

147. Ubhi K, Low P, Masliah E. Multiple system atrophy: a clinical and neuropathological perspective. Trends Neurosci. (2011) 34:581-90. doi: 10.1016/j.tins.2011.08.003

148. Forman MS, Zhukareva V, Bergeron C, Chin SS-M, Grossman M, Clark C, et al. Signature tau neuropathology in gray and white matter of corticobasal degeneration. Am J Pathol. (2002) 160:204553. doi: 10.1016/S0002-9440(10)61154-6

149. Dickson DW, Ahmed Z, Algom AA, Tsuboi Y, Josephs KA. Neuropathology of variants of progressive supranuclear palsy. Curr Opin Neurol. (2010) 23:924. doi: 10.1097/WCO.0b013e32833be924

150. Sale MV, Nordstrom MA, Brophy BP, Thompson PD. Pallidotomy does not ameliorate abnormal intracortical inhibition in Parkinson's disease. J Clin Neurosci. (2010) 17:711-6. doi: 10.1016/j.jocn.2009.09.038
151. Leon-Sarmiento FE, Rizzo-Sierra CV, Bayona EA, Bayona-Prieto J, Doty RL, Bara-Jimenez W. Novel mechanisms underlying inhibitory and facilitatory transcranial magnetic stimulation abnormalities in parkinson's disease. Arch Med Res. (2013) 44:221-8. doi: 10.1016/j.arcmed.2013.03.003

152. Ni Z, Bahl N, Gunraj CA, Mazzella F, Chen R. Increased motor cortical facilitation and decreased inhibition in Parkinson disease. Neurology. (2013) 80:1746-53. doi: 10.1212/WNL.0b013e3182919029

153. MacKinnon CD, Gilley EA, Weis-McNulty A, Simuni T. Pathways mediating abnormal intracortical inhibition in Parkinson's disease. Ann Neurol. (2005) 58:516-24. doi: 10.1002/ana.20599

154. Schneider SA, Talelli P, Cheeran BJ, Khan NL, Wood NW, Rothwell JC, et al. Motor cortical physiology in patients and asymptomatic carriers of parkin gene mutations. Mov Disord. (2008) 23:1812-9. doi: 10.1002/mds.22025

155. Chu J, Wagle-Shukla A, Gunraj C, Lang AE, Chen R. Impaired presynaptic inhibition in the motor cortex in Parkinson disease. Neurology. (2009) 72:842-9. doi: 10.1212/01.wnl.0000343881.27524.e8

156. Vacherot F, Attarian S, Vaugoyeau M, Azulay J-P. A motor cortex excitability and gait analysis on parkinsonian patients: motor cortex excitability and gait analysis. Mov Disord. (2010) 25:2747-55. doi: 10.1002/mds.23378

157. Lewis GN. Altered sensorimotor integration in Parkinson's disease. Brain. (2002) 125:2089-99. doi: 10.1093/brain/awf200

158. Bares M, Kanovsky $\mathrm{P}$, Klajblova H, Rektor I. Intracortical inhibition and facilitation are impaired in patients with early Parkinson's disease: a paired TMS study. Eur J Neurol. (2003) 10:385-9. doi: 10.1046/j.1468-1331.2003.00610.x

159. Kojovic M, Kassavetis P, Bologna M, Pareés I, Rubio-Agusti I, Beraredelli A, et al. Transcranial magnetic stimulation follow-up study in early Parkinson's disease: a decline in compensation with disease progression?: decline in compensatory changes with PD progression. Mov Disord. (2015) 30:1098106. doi: $10.1002 / \mathrm{mds} .26167$

160. Bologna M, Guerra A, Paparella G, Giordo L, Alunni Fegatelli D, Vestri AR, et al. Neurophysiological correlates of bradykinesia in Parkinson's disease. Brain. (2018) 141:2432-44. doi: 10.1093/brain/awy155

161. Sailer A. Short and long latency afferent inhibition in Parkinson's disease. Brain. (2003) 126:1883-94. doi: 10.1093/brain/awg183

162. Nardone R, Florio I, Lochner P, Tezzon F. Cholinergic cortical circuits in Parkinson's disease and in progressive supranuclear palsy: a transcranial magnetic stimulation study. Exp Brain Res. (2005) 163:128-31. doi: 10.1007/s00221-005-2228-7

163. Manganelli F, Vitale C, Santangelo G, Pisciotta C, Iodice R, Cozzolino $A$, et al. Functional involvement of central cholinergic circuits and visual hallucinations in Parkinson's disease. Brain. (2009) 132:23505. doi: 10.1093/brain/awp166

164. Celebi O, Temuçin ÇM, Elibol B, Saka E. Short latency afferent inhibition in Parkinson's disease patients with dementia. Mov Disord. (2012) 27:10525. doi: 10.1002/mds. 25040

165. Yarnall AJ, Rochester L, Baker MR, David R, Khoo TK, Duncan GW, et al. Short latency afferent inhibition: a biomarker for mild cognitive impairment in Parkinson's disease?: short latency afferent inhibition in PD-MCI. Mov Disord. (2013) 28:1285-8. doi: 10.1002/mds.25360

166. Picillo M, Dubbioso R, Iodice R, Iavarone A, Pisciotta C, Spina E, et al. Shortlatency afferent inhibition in patients with Parkinson's disease and freezing of gait. J Neural Transm. (2015) 122:1533-40. doi: 10.1007/s00702-015-1428-y

167. Cantello R, Tarletti R, Varrasi C, Cecchin M, Monaco F. Cortical inhibition in Parkinson's disease: new insights from early, untreated patients. Neuroscience. (2007) 150:64-71. doi: 10.1016/j.neuroscience.2007.08.033

168. Spagnolo F, Coppi E, Chieffo R, Straffi L, Fichera M, Nuara $\mathrm{A}$, et al. Interhemispheric balance in Parkinson's disease: a transcranial magnetic stimulation study. Brain Stimul. (2013) 6:892-7. doi: 10.1016/j.brs.2013.05.004

169. Frasson E, Bertolasi L, Bertasi V, Fusina S, Bartolomei L, Vicentini $\mathrm{S}$, et al. Paired transcranial magnetic stimulation for the early diagnosis of corticobasal degeneration. Clin Neurophysiol. (2003) 114:272-8. doi: 10.1016/S1388-2457(02)00340-1

170. Benussi A, Dell'Era V, Cantoni V, Ferrari C, Caratozzolo S, Rozzini L, et al. Discrimination of atypical parkinsonisms with transcranial magnetic stimulation. Brain Stimul. (2018) 11:366-73. doi: 10.1016/j.brs.2017. 11.013 
171. Conte A, Belvisi D, Bologna M, Ottaviani D, Fabbrini G, Colosimo $\mathrm{C}$, et al. Abnormal cortical synaptic plasticity in primary motor area in progressive supranuclear palsy. Cerebral Cortex. (2012) 22:693700. doi: 10.1093/cercor/bhr149

172. Wittstock M, Pohley I, Walter U, Grossmann A, Benecke R, Wolters A. Interhemispheric inhibition in different phenotypes of progressive supranuclear palsy. J Neural Transm. (2013) 120:453-61. doi: 10.1007/s00702-012-0879-7

173. Abbruzzese G, Marchese R, Trompetto C. Sensory and motor evoked potentials in multiple system atrophy: a comparative study with Parkinson's disease. Mov Disord. (1997) 12:315-21. doi: 10.1002/mds.870 120309

174. Eusebio A, Azulay J-P, Witjas T, Rico A, Attarian S. Assessment of cortico-spinal tract impairment in multiple system atrophy using transcranial magnetic stimulation. Clin Neurophysiol. (2007) 118:81523. doi: 10.1016/j.clinph.2007.01.004

175. Schrader C, Peschel T, Däuper J, Rollnik JD, Dengler R, Kossev AR. Changes in processing of proprioceptive information in Parkinson's disease and multiple system atrophy. Clin Neurophysiol. (2008) 119:113946. doi: 10.1016/j.clinph.2008.01.005

176. Celebi O, Temuçin ÇM, Elibol B, Saka E. Cognitive profiling in relation to short latency afferent inhibition of frontal cortex in multiple system atrophy. Parkinson Related Disord. (2014) 20:632-6. doi: 10.1016/j.parkreldis.2014.03.012

177. Correia Guedes L, Mestre T, Outeiro TF, Ferreira JJ. Are genetic and idiopathic forms of Parkinson's disease the same disease? I Neurochem. (2020) 152:515-22. doi: 10.1111/jnc.14902

178. Rosa A, Volpe G, Marcantonio L, Santoro L, Brice A, Filla $A$, et al. Neurophysiological evidence of corticospinal tract abnormality in patients with Parkin mutations. J Neurol. (2006) 253:275-9. doi: 10.1007/s00415-006-0096-0

179. Kojovic M, Kassavetis P, Pareés I, Georgiev D, Rocchi L, Balint B, et al. Pathophysiological heterogeneity in Parkinson's disease: neurophysiological insights from LRRK2 mutations: pathophysiological heterogeneity in LARRK2 PD. Mov Disord. (2017) 32:1333-5. doi: 10.1002/mds. 27091

180. Ponzo V, Di Lorenzo F, Brusa L, Schirinzi T, Battistini S, Ricci C, et al. Impaired intracortical transmission in G2019S leucine rich-repeat kinase Parkinson patients: neurotransmission in LRRK2 PD patients. Mov Disord. (2017) 32:750-6. doi: 10.1002/mds.26931

181. Kimiskidis VK, Papayiannopoulos S, Sotirakoglou K, Karakasis H, Katsarou $Z$, Kazis DA, et al. The cortical excitability profile of patients with the G209A SNCA mutation versus patients with sporadic Parkinson's disease: a transcranial magnetic stimulation study. Neurophysiol Clin. (2018) 48:2036. doi: 10.1016/j.neucli.2018.04.002

182. Weissbach A, Bäumer T, Pramstaller PP, Brüggemann N, Tadic V, Chen $\mathrm{R}$, et al. Abnormal premotor-motor interaction in heterozygous Parkin - and Pink1 mutation carriers. Clin Neurophysiol. (2017) 128:27580. doi: 10.1016/j.clinph.2016.10.007

183. Eggers C, Fink GR, Nowak DA. Theta burst stimulation over the primary motor cortex does not induce cortical plasticity in Parkinson's disease. $J$ Neurol. (2010) 257:1669-74. doi: 10.1007/s00415-010-5597-1

184. Eggers C, Günther M, Rothwell J, Timmermann L, Ruge D. Theta burst stimulation over the supplementary motor area in Parkinson's disease. $J$ Neurol. (2015) 262:357-64. doi: 10.1007/s00415-014-7572-8

185. Suppa A, Iezzi E, Conte A, Belvisi D, Marsili L, Modugno N, et al. Dopamine influences primary motor cortex plasticity and dorsal premotor-to-motor connectivity in Parkinson's disease. Cerebral Cortex. (2010) 20:222433. doi: 10.1093/cercor/bhp288

186. Benninger DH, Iseki K, Kranick S, Luckenbaugh DA, Houdayer E, Hallett $\mathrm{M}$. Controlled study of $50-\mathrm{Hz}$ repetitive transcranial magnetic stimulation for the treatment of Parkinson disease. Neurorehabil Neural Repair. (2012) 26:1096-105. doi: 10.1177/1545968312445636

187. Schirinzi T, Di Lorenzo F, Ponzo V, Palmieri MG, Bentivoglio AR, Schillaci $\mathrm{O}$, et al. Mild cerebello-thalamo-cortical impairment in patients with normal dopaminergic scans (SWEDD). Parkinson Related Disord. (2016) 28:238. doi: 10.1016/j.parkreldis.2016.03.023
188. Kishore A, Joseph T, Velayudhan B, Popa T, Meunier S. Early, severe and bilateral loss of LTP and LTD-like plasticity in motor cortex (M1) in de novo Parkinson's disease. Clin Neurophysiol. (2012) 123:8228. doi: 10.1016/j.clinph.2011.06.034

189. Suppa A, Marsili L, Belvisi D, Conte A, Iezzi E, Modugno N, et al. Lack of LTP-like plasticity in primary motor cortex in Parkinson's disease. Exp Neurol. (2011) 227:296-301. doi: 10.1016/j.expneurol.2010.11.020

190. Lu M-K, Chen C-M, Duann J-R, Ziemann U, Chen J-C, Chiou S-M, et al. Investigation of motor cortical plasticity and corticospinal tract diffusion tensor imaging in patients with Parkinson's disease and essential tremor. PLoS ONE. (2016) 11:e0162265. doi: 10.1371/journal.pone.0162265

191. Rodrigues JP, Walters SE, Stell R, Mastaglia FL, Thickbroom GW. Spiketiming-related plasticity is preserved in Parkinson's disease and is enhanced by dopamine: evidence from transcranial magnetic stimulation. Neurosci Lett. (2008) 448:29-32. doi: 10.1016/j.neulet.2008.10.048

192. Zamir O, Gunraj C, Ni Z, Mazzella F, Chen R. Effects of theta burst stimulation on motor cortex excitability in Parkinson's disease. Clin Neurophysiol. (2012) 123:815-21. doi: 10.1016/j.clinph.2011.07.051

193. Bagnato S, Agostino R, Modugno N, Quartarone A, Berardelli A. Plasticity of the motor cortex in Parkinson's disease patientson andoff therapy. Mov Disord. (2006) 21:639-45. doi: 10.1002/mds.20778

194. Fierro B, Brighina F, D’Amelio M, Daniele O, Lupo I, Ragonese P, et al. Motor intracortical inhibition in PD: L-DOPA modulation of high-frequency rTMS effects. Exp Brain Res. (2008) 184:521-8. doi: 10.1007/s00221-007-1121-y

195. Degardin A, Devos D, Defebvre L, Destée A, Plomhause L, Derambure P, et al. Effect of intermittent theta-burst stimulation on akinesia and sensorimotor integration in patients with Parkinson's disease: iTBS in Parkinson's disease. Eur J Neurosci. (2012) 36:2669-78. doi: 10.1111/j.1460-9568.2012.08158.x

196. Huang Y-Z, Rothwell JC, Lu C-S, Chuang W-L, Chen R-S. Abnormal bidirectional plasticity-like effects in Parkinson's disease. Brain. (2011) 134:2312-20. doi: 10.1093/brain/awr158

197. Di Biasio F, Conte A, Bologna M, Iezzi E, Rocchi L, Modugno N, et al. Does the cerebellum intervene in the abnormal somatosensory temporal discrimination in Parkinson's disease? Parkinson Related Disord. (2015) 21:789-92. doi: 10.1016/j.parkreldis.2015.04.004

198. Galea JM, Jayaram G, Ajagbe L, Celnik P. Modulation of cerebellar excitability by polarity-specific noninvasive direct current stimulation. $J$ Neurosci. (2009) 29:9115-22. doi: 10.1523/JNEUROSCI.2184-09.2009

199. Carrillo F, Palomar FJ, Conde V, Diaz-Corrales FJ, Porcacchia P, Fernándezdel-Olmo M, et al. Study of cerebello-thalamocortical pathway by transcranial magnetic stimulation in Parkinson's disease. Brain Stimul. (2013) 6:582-9. doi: 10.1016/j.brs.2012.12.004

200. Ni Z, Pinto AD, Lang AE, Chen R. Involvement of the cerebellothalamocortical pathway in Parkinson disease. Ann Neurol. (2010) 68:816-24. doi: 10.1002/ana.22221

201. Perretti A, De Rosa A, Marcantonio L, Iodice V, Estraneo A, Manganelli F, et al. Neurophysiological evaluation of motor corticospinal pathways by TMS in idiopathic early-onset Parkinson's disease. Clin Neurophysiol. (2011) 122:546-9. doi: 10.1016/j.clinph.2010.07.016

202. Jahanshahi M, Brown RG, Marsden D. Simple and choice reaction time and the use of advance information for motor preparation in Parkinson's disease. Brain. (1992) 115:539-64. doi: 10.1093/brain/115.2.539

203. Jahanshahi M, Obeso I, Baunez C, Alegre M, Krack P. Parkinson's disease, the subthalamic nucleus, inhibition, and impulsivity. Mov Disord. (2015) 30:128-40. doi: 10.1002/mds.26049

204. Jahanshahi M, Obeso I, Rothwell JC, Obeso JA. A fronto-striatosubthalamic-pallidal network for goal-directed and habitual inhibition. Nat Rev Neurosci. (2015) 16:719-32. doi: 10.1038/nrn4038

205. Obeso I, Wilkinson L, Casabona E, Speekenbrink M, Bringas ML, Álvarez M, Álvarez L, Pavón N, et al. The subthalamic nucleus and inhibitory control: impact of subthalamotomy in Parkinson's disease. Brain. (2014) 137:1470-80. doi: 10.1093/brain/awu058

206. Jahanshahi M, Rothwell JC. Inhibitory dysfunction contributes to some of the motor and non-motor symptoms of movement disorders and psychiatric disorders. Philos Trans $R$ Soc B Biol Sci. (2017) 372:198. doi: $10.1098 /$ rstb.2016.0198 
207. Bologna M, Paparella G, Fasano A, Hallett M, Berardelli A. Evolving concepts on bradykinesia. Brain. (2020) 143:727-50. doi: 10.1093/brain/awz344

208. Palomar FJ, Conde V, Carrillo F, Fernández-del-Olmo M, Koch G, Mir P. Parieto-motor functional connectivity is impaired in Parkinson's disease. Brain Stimul. (2013) 6:147-54. doi: 10.1016/j.brs.2012.03.017

209. Bareš M, Kanovský P, Rektor I. Disturbed intracortical excitability in early Parkinson's disease is 1-DOPA dose related: a prospective 12month paired TMS study. Parkinson Related Disord. (2007) 13:48994. doi: 10.1016/j.parkreldis.2007.02.008

210. Ponzo V, Picazio S, Benussi A, Di Lorenzo F, Brusa L, Caltagirone C, et al. Altered inhibitory interaction among inferior frontal and motor cortex in $\mathrm{L}$ dopa-induced dyskinesias: abnormal ifc- $\mathrm{m} 1$ connectivity in lids. Mov Disord. (2016) 31:755-9. doi: 10.1002/mds.26520

211. Guerra A, Suppa A, D'Onofrio V, Di Stasio F, Asci F, Fabbrini G, et al. Abnormal cortical facilitation and L-dopa-induced dyskinesia in Parkinson's disease. Brain Stimul. (2019) 12:1517-25. doi: 10.1016/j.brs.2019.06.012

212. Barbin L, Leux C, Sauleau P, Meyniel C, Nguyen J-M, Pereon Y, et al. Non-homogeneous effect of levodopa on inhibitory circuits in Parkinson's disease and dyskinesia. Parkinson Relat Disord. (2013) 19:16570. doi: 10.1016/j.parkreldis.2012.08.012

213. Casarotto S, Turco F, Comanducci A, Perretti A, Marotta G, Pezzoli G, et al. Excitability of the supplementary motor area in Parkinson's disease depends on subcortical damage. Brain Stimul. (2019) 12:15260. doi: $10.1016 /$ j.brs.2018.10.011

214. Turco F, Canessa A, Olivieri C, Pozzi NG, Palmisano C, Arnulfo G, et al. Cortical response to levodopa in Parkinson's disease patients with dyskinesias. Eur J Neurosci. (2018) 48:2362-73. doi: 10.1111/ejn. 14114

215. Espay AJ, Lang AE. Common myths in the use of levodopa in parkinson disease: when clinical trials misinform clinical practice. JAMA Neurol. (2017) 74:633-4. doi: 10.1001/jamaneurol.2017.0348

216. Zittel S, Heinbokel C, van der Vegt JPM, Niessen E, Buhmann C, Gerloff C, et al. Effects of dopaminergic treatment on functional corticocortical connectivity in Parkinson's disease. Exp Brain Res. (2015) 233:32937. doi: 10.1007/s00221-014-4115-6

217. Morgante F, Espay AJ, Gunraj C, Lang AE, Chen R. Motor cortex plasticity in Parkinson's disease and levodopa-induced dyskinesias. Brain. (2006) 129:1059-69. doi: 10.1093/brain/awl031

218. Pierantozzi M, Palmieri M, Marciani M, Bernardi G, Giacomini P, Stanzione P. Effect of apomorphine on cortical inhibition in Parkinson's disease patients: a transcranial magnetic stimulation study. Exp Brain Res. (2001) 141:52-62. doi: 10.1007/s002210100839

219. Kawashima S, Ueki Y, Mima T, Fukuyama H, Ojika K, Matsukawa $\mathrm{N}$. Differences in dopaminergic modulation to motor cortical plasticity between Parkinson's disease and multiple system atrophy. PLoS ONE. (2013) 8:e62515. doi: 10.1371/journal.pone.0062515

220. Kahan J, Urner M, Moran R, Flandin G, Marreiros A, Mancini L, et al. Resting state functional MRI in Parkinson's disease: the impact of deep brain stimulation on "effective" connectivity. Brain. (2014) 137:113044. doi: 10.1093/brain/awu027

221. Kahan J, Mancini L, Flandin G, White M, Papadaki A, Thornton J, et al. Deep brain stimulation has state-dependent effects on motor connectivity in Parkinson's disease. Brain. (2019) 142:2417-31. doi: 10.1093/brain/awz164

222. Cunic D, Roshan L, Khan FI, Lozano AM, Lang AE, Chen R. Effects of subthalamic nucleus stimulation on motor cortex excitability in Parkinson's disease. Neurology. (2002) 58:1665-72. doi: 10.1212/wnl.58.11.1665

223. Däuper J, Peschel T, Schrader C, Kohlmetz C, Joppich G, Nager $\mathrm{W}$, et al. Effects of subthalamic nucleus (STN) stimulation on motor cortex excitability. (2002) 59:700-6. doi: 10.1212/WNL.59. 5.700

224. Pierantozzi M, Palmieri MG, Mazzone P, Marciani MG, Rossini PM, Stefani A, et al. Deep brain stimulation of both subthalamic nucleus and internal globus pallidus restores intracortical inhibition in Parkinson's disease paralleling apomorphine effects: a paired magnetic stimulation study. Clin Neurophysiol. (2002) 113:108-13. doi: 10.1016/S1388-2457(01) 00694-0

225. Sailer A, Cunic DI, Paradiso GO, Gunraj CA, Wagle-Shukla A, Moro E, et al. Subthalamic nucleus stimulation modulates afferent inhibition in Parkinson disease. Neurology.

(2007) 68:356-63. doi: 10.1212/01.wnl.0000252812.95774.aa

226. Fraix V, Pollak P, Vercueil L, Benabid A-L, Mauguière F. Effects of subthalamic nucleus stimulation on motor cortex excitability in Parkinson's disease. Clin Neurophysiol. (2008) 119:2513-8. doi: 10.1016/j.clinph.2008.07.217

227. Pötter-Nerger M, Ilic TV, Siebner HR, Deuschl G, Volkmann J. Subthalamic nucleus stimulation restores corticospinal facilitation in Parkinson's disease. Mov Disord. (2008) 23:2210-5. doi: 10.1002/mds.22284

228. Bäumer T, Hidding U, Hamel W, Buhmann C, Moll CKE, Gerloff C, et al. Effects of DBS, premotor rTMS, and levodopa on motor function and silent period in advanced Parkinson's disease. Mov Disord. (2009) 24:67266. doi: $10.1002 / \mathrm{mds} .22417$

229. Cernera S, Okun MS, Gunduz A. A review of cognitive outcomes across movement disorder patients undergoing deep brain stimulation. Front Neurol. (2019) 10:419. doi: 10.3389/fneur.2019.00419

230. Bickel S, Alvarez L, Macias R, Pavon N, Leon M, Fernandez C, et al. Cognitive and neuropsychiatric effects of subthalamotomy for Parkinson's disease. Parkinson Relat Disord. (2010) 16:535539. doi: 10.1016/j.parkreldis.2010.06.008

231. Casula EP, Stampanoni Bassi M, Pellicciari MC, Ponzo V, Veniero D, Peppe A, et al. Subthalamic stimulation and levodopa modulate cortical reactivity in Parkinson's patients. Parkinson Relat Disord. (2017) 34:317. doi: 10.1016/j.parkreldis.2016.10.009

232. Rawji V, Kaczmarczyk I, Rocchi L, Rothwell JC, Sharma N. Short interval intracortical inhibition as measured by TMS-EEG. bioRxiv. (2019). doi: 10.1101/802504

233. Ziemann U, Ridding MC. Determinants of the induction of cortical plasticity by non-invasive brain stimulation in healthy subjects. J Physiol. (2010) 588(Pt 13):2291-304. doi: 10.1113/jphysiol.2010.190314

234. Fried PJ, Jannati A, Davila-Pérez P, Pascual-Leone A. Reproducibility of single-pulse, paired-pulse, and intermittent theta-burst TMS measures in healthy aging, type-2 diabetes, and Alzheimer's disease. Front Aging Neurosci. (2017) 9:263. doi: 10.3389/fnagi.2017.00263

235. Shibuya K, Simon NG, Geevasinga N, Menon P, Howells J, Park SB, et al. The evolution of motor cortical dysfunction in amyotrophic lateral sclerosis. Clin Neurophysiol. (2017) 128:1075-82. doi: 10.1016/j.clinph.2017.03.004

236. Selvackadunco S, Langford K, Shah Z, Hurley S, Bodi I, King $\mathrm{A}$, et al. Comparison of clinical and neuropathological diagnoses of neurodegenerative diseases in two centres from the Brains for Dementia Research (BDR) cohort. J Neural Transm. (2019) 126:327-37. doi: 10.1007/s00702-018-01967-w

237. Young PNE, Estarellas M, Coomans E, Srikrishna M, Beaumont H, Maass $A$, et al. Imaging biomarkers in neurodegeneration: current and future practices. Alz Res Therapy. (2020) 12:49. doi: 10.1186/s13195-020-00612-7

238. Shahnawaz M, Mukherjee A, Pritzkow S, Mendez N, Rabadia P, Liu X, et al. Discriminating $\alpha$-synuclein strains in Parkinson's disease and multiple system atrophy. Nature. (2020) 578:273-7. doi: 10.1038/s41586-020-1984-7

239. Simrén J, Ashton NJ, Blennow K, Zetterberg H. An update on fluid biomarkers for neurodegenerative diseases: recent success and challenges ahead. Curr Opin Neurobiol. (2020) 61:29-39. doi: 10.1016/j.conb.2019.11.019

240. Casula EP, Mayer IMS, Desikan M, Tabrizi SJ, Rothwell JC, Orth M. Motor cortex synchronization influences the rhythm of motor performance in premanifest Huntington's disease. Mov Disord. (2018) 33:440-8. doi: $10.1002 / \mathrm{mds} .27285$

Conflict of Interest: The authors declare that the research was conducted in the absence of any commercial or financial relationships that could be construed as a potential conflict of interest.

Copyright $\odot 2020$ Rawji, Latorre, Sharma, Rothwell and Rocchi. This is an openaccess article distributed under the terms of the Creative Commons Attribution License (CC BY). The use, distribution or reproduction in other forums is permitted, provided the original author(s) and the copyright owner(s) are credited and that the original publication in this journal is cited, in accordance with accepted academic practice. No use, distribution or reproduction is permitted which does not comply with these terms. 